\title{
Aeromonas salmonicida Infection Only Moderately Regulates Expression of Factors Contributing to Toll-Like Receptor Signaling but Massively Activates the Cellular and Humoral Branches of Innate Immunity in Rainbow Trout (Oncorhynchus mykiss)
}

\author{
Andreas Brietzke, ${ }^{1}$ Tomáš Korytár̆, ${ }^{2,3}$ Joanna Jaros, ${ }^{2}$ Bernd Köllner, ${ }^{2}$ \\ Tom Goldammer, ${ }^{1}$ Hans-Martin Seyfert, ${ }^{1}$ and Alexander Rebl ${ }^{1}$ \\ ${ }^{1}$ Leibniz Institute for Farm Animal Biology (FBN), Institute of Genome Biology, Wilhelm-Stahl-Allee 2, 18196 Dummerstorf, Germany \\ ${ }^{2}$ Friedrich Loeffler Institute, Federal Research Institute for Animal Health, Institute of Immunology, \\ Südufer 10, Insel Riems, 17493 Greifswald, Germany \\ ${ }^{3}$ Department of Pathobiology, School of Veterinary Medicine, University of Pennsylvania, 3800 Spruce Street, \\ Philadelphia, PA 19104, USA \\ Correspondence should be addressed to Alexander Rebl; rebl@fbn-dummerstorf.de
}

Received 5 February 2015; Accepted 15 June 2015

Academic Editor: Cornelis J. M. Melief

Copyright ( 2015 Andreas Brietzke et al. This is an open access article distributed under the Creative Commons Attribution License, which permits unrestricted use, distribution, and reproduction in any medium, provided the original work is properly cited.

Toll-like receptors (TLRs) are known to detect a defined spectrum of microbial structures. However, the knowledge about the specificity of teleost Tlr factors for distinct pathogens is limited so far. We measured baseline expression profiles of 18 tlr genes and associated signaling factors in four immune-relevant tissues of rainbow trout Oncorhynchus mykiss. Intraperitoneal injection of a lethal dose of Aeromonas salmonicida subsp. salmonicida induced highly increased levels of cytokine mRNAs during a 72-hour postinfection (hpi) period. In contrast, only the fish-specific tlr22a2 and the downstream factor irakl featured clearly increased transcript levels, while the mRNA concentrations of many other tlr genes decreased. Flow cytometry quantified cell trafficking after infection indicating a dramatic influx of myeloid cells into the peritoneum and a belated low level immigration of lymphoid cells. $\mathrm{T}$ and B lymphocytes were differentiated with RT-qPCR revealing that B lymphocytes emigrated from and Tymphocytes immigrated into head kidney. In conclusion, no specific TLR can be singled out as a dominant receptor for A. salmonicida. The recruitment of cellular factors of innate immunity rather than induced expression of pathogen receptors is hence of key importance for mounting a first immune defense against invading A. salmonicida.

\section{Introduction}

The vertebrate immune system consists of a conserved innate system complemented by a highly specialized (adaptive) immune system. Both branches of immunity communicate and collaborate in a bipartisan way to ensure the effective destruction of potentially harmful microbes [1]. Pattern recognition receptors (PRRs) are crucial germ-line encoded components of the innate branch, as they recognize directly and immediately conserved microbial structures and molecular motifs (MAMPs, microbe-associated molecular patterns, previously known as PAMPs) as well as immunogenic endogenous molecules released from the infected host (DAMPs, damage-associated molecular patterns) [2-4].

Toll-like receptors (TLRs) are the best characterized innate immune receptors. More than 20 TLRs clustered in six subfamilies have been identified in more than a dozen of fish species [5-7] (Figure 1). They provide a wide spectrum 


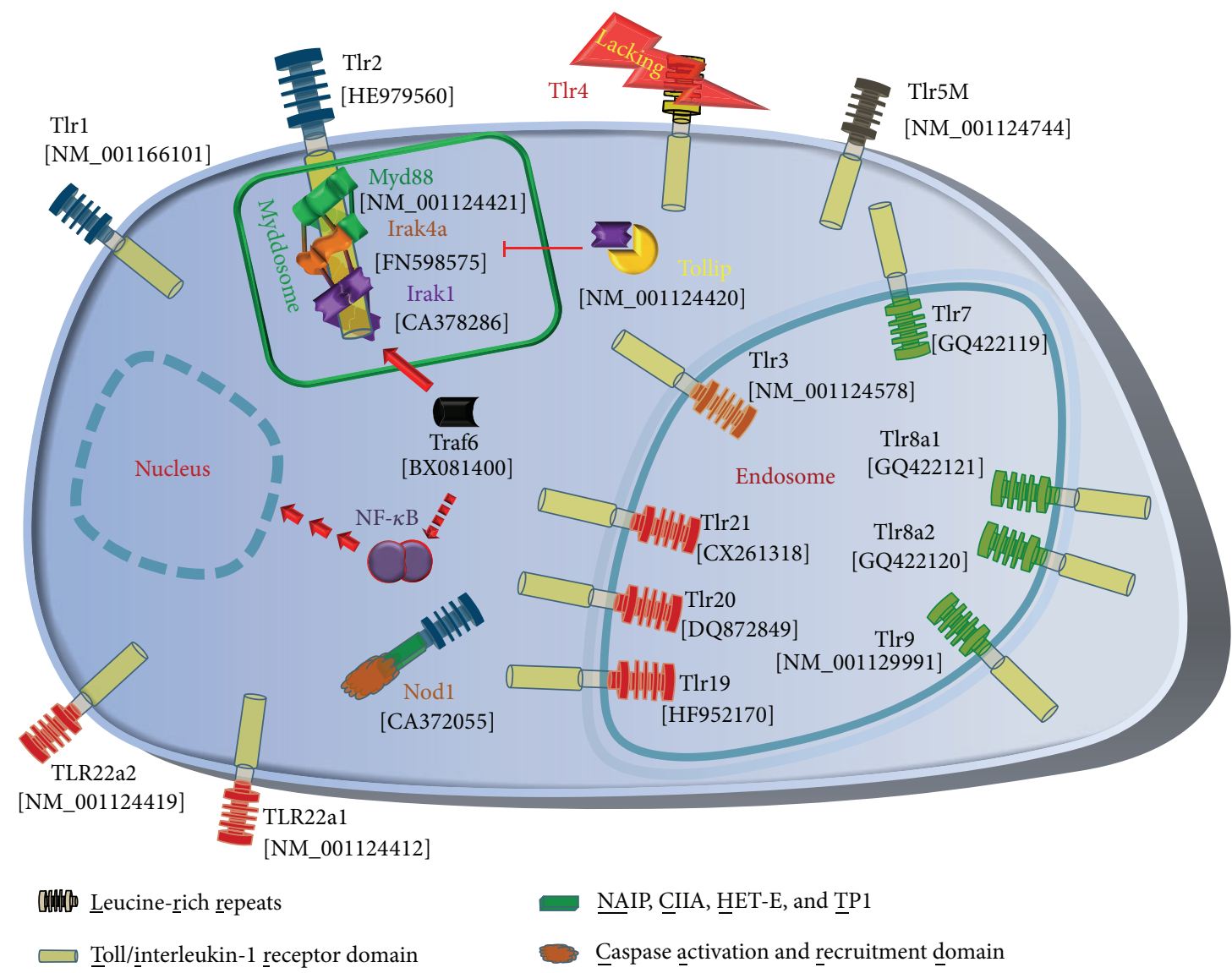

FIGURE 1: Pathogen recognition in trout. Toll-like receptors, Nod1, and downstream factors as known from trout are listed with their GenBank accession numbers. Different colors of the LRR regions factors indicate the membership to individual Tlr families (TLR1 (blue), Tlr3 (orange), Tlr5 (black), Tlr7 (green), and Tlr11 (red)). Notably, a Tlr4 ortholog is absent in salmonid fish (marked with a flash). The Myddosome consisting of Myd88, Irak4a, and Irak1 (inside the green box) binds to the activated Tlr and recruits Traf6 and further downstream factors (indicated with a broken arrow), which in turn activate NF- $\kappa$ B. Tollip functionally inhibits Irak1 by preventing its recruitment into the Myddosome complex.

for recognizing the plethora of aquatic pathogens. Upon ligand binding, TLRs dimerize and undergo conformational changes to recruit the Myddosome to the activated toll/interleukin-1 receptor domain (TIR) [8]. In mammals, this helical structure consists of six MYD88 (myeloid differentiation primary response protein 88 ) adaptor molecules, onto which a layer of four IRAK4 (interleukin-1 receptorassociated kinase 4) serine/threonine kinases and another layer of four IRAK2 or IRAK1 factors are assembled [8]. The composition of teleost Myddosome is unknown so far, although functional interaction of the complex Myd88IRAK4a with the TIR domain has been reported [9]. However, no IRAK2 factor has yet been found in any teleostean fish species $[5,6]$.

The activated receptor complex promotes the dissociation of IRAK1 from its functional repressor TOLLIP (tollinteracting protein) allowing its association with TRAF6 (TNF receptor-associated factor 6) and further downstream factors to activate either NF- $\kappa \mathrm{B}$ or interferon regulatory transcription factors or mitogen-activated protein kinases [10]. This TLR-MYD88-IRAK-TRAF6 signaling pathway is well conserved, not only in vertebrates but also in Drosophila $[11,12]$. The activated cascade results in enhanced expression of immune factors such as cytokines provoking inflammation and allowing the communication with the adaptive branch of immunity [12].

The Gram-negative bacterium Aeromonas salmonicida ssp. salmonicida is the causative agent of furunculosis, a serious disease of salmonid fish inducing high mortality even after a low-dose intraperitoneal injection [13]. Pathogenic challenges induce not only the massive activation of proinflammatory mediators [14-17], but also enhanced transcription of tlr-encoding genes in fish [18-20] as reported previously for mammals [21-23]. The dominant MAMP from Gram-negative bacteria is lipopolysaccharide (LPS), known in mammals to be specifically and solely recognized by TLR 4 [24]. No TLR4 ortholog has been identified so far in salmonid fish, and LPS recognition in bony fish is unclear to date $[6,25,26]$. Moreover, modulation of the expression pattern of the entire TLR panel in response to A. salmonicida has not been reported from rainbow trout. We therefore profiled the expression of 13 tlrs belonging to five subfamilies of 
these receptors (Figure 1) in immune tissues (spleen, head kidney, liver, and thymus) from healthy and A. salmonicidainfected rainbow trout. Moreover, we also included other genes encoding downstream factors of TLR signaling into analysis, that is, the TLR adapter myd88 [27]; the key kinases irak4a [9] and irakl; the NF- $\kappa \mathrm{B}$-activating factor traf6; and the inhibitor of TLR signaling, tollip [28]. This panel of candidate factors should provide a comprehensive overview of the transcriptional regulation of TLR signaling in trout during A. salmonicida infection.

\section{Materials and Methods}

2.1. Experimental Infection and Tissue Sampling. Rainbow trout ("steelhead"; Trout Lodge, Tacoma, USA) were kept in 300-1 tanks at $15^{\circ} \mathrm{C}$ in partially recirculating water systems. The water quality was monitored daily. The light period was $12 \mathrm{~h}$ per day and night. Fish were fed with commercial dry pellets.

A. salmonicida subsp. salmonicida (wild type strain JF 2267) was used for experimental infection of trout. The bacteria were cultivated from cryoconserved batches (Microbank, PRO-LAB Diagnostics, Cheshire, UK) in LB broth (SIFIN) at $15^{\circ} \mathrm{C}$ for $72 \mathrm{~h}$. The initial cultures were checked for purity by Gram-staining and observation of cell morphology. The bacterial suspension was concentrated by centrifugation (4300 $\mathrm{rpm}, 10 \mathrm{~min}, 4^{\circ} \mathrm{C}$ ). The bacterial pellet was washed once in sterile $0.9 \%$ sodium chloride solution and diluted to $1 \times 10^{8}$ bacteria/mL.

We injected lethal doses of $A$. salmonicida to conceivably induce uniform physiological reactions in all individual fish. One group of fish $(n=30)$ was infected by peritoneal injection with $200 \mu \mathrm{L}$ PBS (phosphate-buffered saline) containing $1 \times 10^{7}$ A. salmonicida while a control group $(n=5)$ received $200 \mu \mathrm{L}$ PBS only. Five fish per group were sampled at 0-, 6-, 12-, 24-, 48-, and 72-hour postinfection (hpi). Peritoneal injection and anaesthetization of rainbow trout with phenoxyethanol prior to sampling were conducted in compliance with terms of the German Animal Welfare Act ( $\$$ 4(3) TierSchG). The experimental protocol was approved by the Animal Care Committee of the State Mecklenburg Western Pomerania (Landesamt für Landwirtschaft, Lebensmittelsicherheit und Fischerei, Mecklenburg-Vorpommern, Germany; LALLF M-V/TSD/7221.3-2.5-008/10). Tissue samples of spleen, head kidney, liver, and thymus were immediately snap-frozen and stored in liquid nitrogen.

2.2. RNA Isolation and cDNA Synthesis. Tissue samples were powdered in a mortar under liquid nitrogen and total RNA was subsequently extracted using QIAzol Lysis Reagent followed by purification with RNeasy Mini spin columns, as provided in the RNeasy Plus Universal Kit (Qiagen, Hilden, Germany). The RNA concentrations were determined with the NanoDrop 2000 photometer (Thermo Scientific, Waltham, MA, USA). $1.5 \mu \mathrm{g}$ total RNA from each sample was transcribed into cDNA using the Super Script II kit (Invitrogen/Life Technologies, Karlsruhe, Germany) and gene-specific antisense oligonucleotides (Table 1).
Complementary DNA aliquots equivalent to an input of 75 ng total RNA were used in subsequent RT-qPCR reactions.

2.3. $R T-q P C R$. We derived rainbow trout specific oligonucleotide primer pairs to amplify cDNA sequence fragments of $13 \mathrm{tlr}$ genes (tlr1, tlr2, tlr3, tlr5, tlr7, tlr8a1, tlr8a2, tlr9, tlr19, tlr20, tlr21, tlr22a1, and tlr22a2); of five genes coding for downstream signaling factors of the TLR pathway (myd88, irak4a, irakl, tollip, and traf6); of the nodl gene (nucleotidebinding oligomerization domain-containing 1) representing an alternative PRR. All relevant GenBank accession codes are indicated in Figure 1. Primers for five cytokine-encoding genes (illb, $\operatorname{tnf}$, il8, il10, and $t g f b)$ and two immune cell marker genes (ighm, trb) were also derived (Table 1). The oligonucleotide primers were designed using the Pyrosequencing Assay Design software v.1.0.6 (Biotage, Uppsala, Sweden). The resulting PCR products were cloned (pGEM-T Easy; Promega, Mannheim, Germany) and sequenced (Applied Biosystems 3130 Genetic Analyzer; Life Technologies) to ensure the authenticity of the respective gene fragments. Primer efficiencies are given in Table 1.

cDNA copy numbers were quantified on the LightCycler 96 System (Roche, Basel, Switzerland) using the SensiFAST SYBR No-ROX Kit (Bioline, Luckenwalde, Germany). After each RT-qPCR run, PCR products were visualized on 3-\% agarose gels to validate product size and quality. Melting curve analyses evaluated the amplification of single products per sample (specific Tm values are listed in Table 1). Standard curves were generated based on 10 -fold dilutions $\left(10^{3}\right.$ to $10^{6}$ copies) of the respective cloned fragments serving as external standards in the analytical runs. Copy numbers were calculated on the basis of linear regression of the standard curve $\left(R^{2}>0.99\right.$ in each case).

2.4. Flow Cytometry. The cells in the peritoneal cavity, the site of experimental infection, were retrieved through lavage with $5 \mathrm{~mL}$ ice-cold PBS containing $5 \mathrm{mM}$ EDTA (ethylenediaminetetraacetic acid). For the analysis of cell number and distribution of lymphoid and myeloid cell populations, $100 \mu \mathrm{L}$ cell suspension was diluted in $300 \mu \mathrm{L}$ PBS/0.01M EDTA solution. Cells counts were acquired by FACSCalibur (Becton Dickinson, Germany) in "HIGH-throughput" mode for 20 seconds. The cell composition was analyzed using a set of monoclonal antibodies as previously described [29]. In brief, the total number of leukocytes was incubated with diluted antibodies for 30 minutes. Antibodies were either directly labeled with fluorochrome or cells were first incubated with an unlabeled specific antibody and subsequently for another 30 minutes with the corresponding mouse isotype-specific antibody, labeled either with fluorescein isothiocyanate (FITC; Rockland, Limerick, PA, USA) or R-phycoerythrin (RPE; Jackson ImmunoResearch Laboratories, West Grove, PA, USA).

2.5. Statistics. The data are presented as the mean \pm standard error of the mean SEM. To assess statistical significances, we performed one-way analysis of variance (ANOVA) followed by Tukey's post hoc test as provided by SigmaPlot 


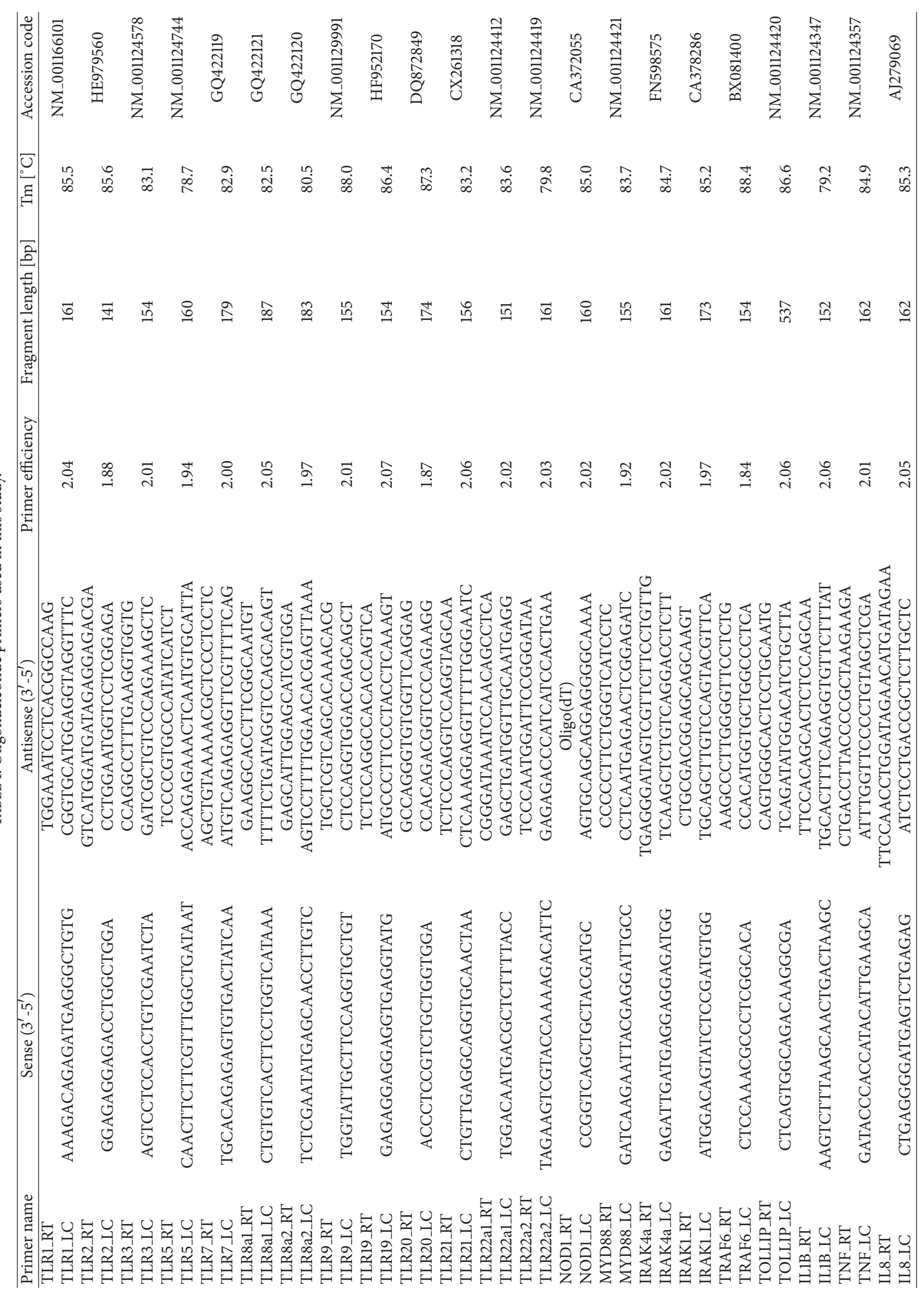




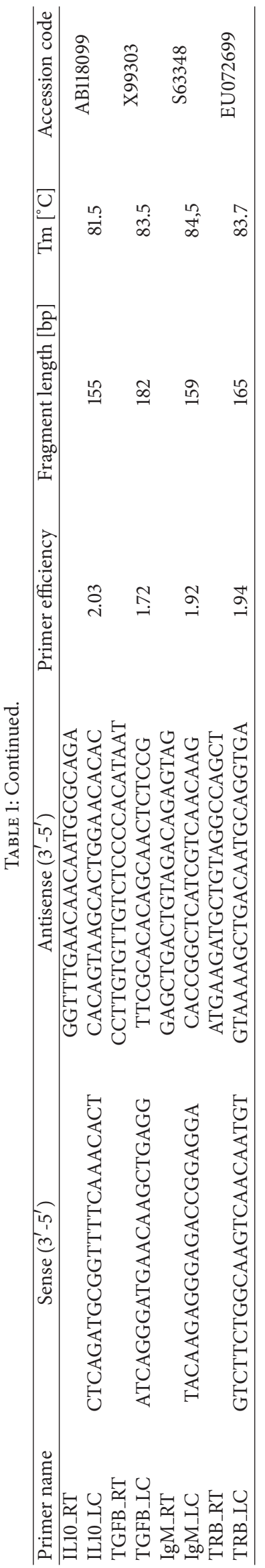




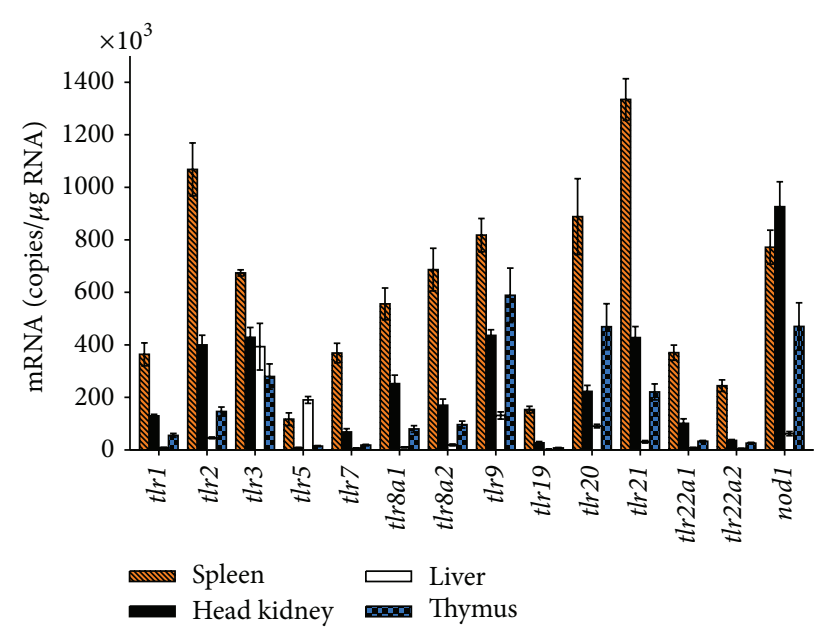

(a)

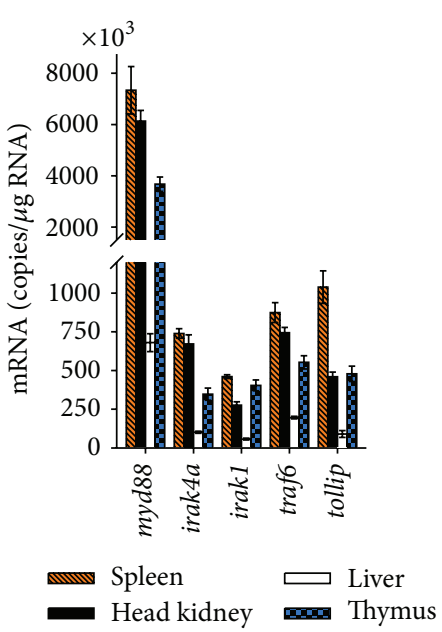

(b)

FIGURE 2: Copy number of (a) PRRs and (b) downstream signaling factors in selected tissues from healthy trout. Quantitative RT-PCR was used to determine the number of transcripts/ $\mu$ g total RNA (ordinate) in spleen (dashed bars), head kidney (filled bars), liver (open bars), and thymus (chequered bars) of five healthy rainbow trout. Bars indicate mean \pm SEM.

(Systat Software Inc., San Jose, CA, USA). $p$ values $<0.05$ were considered as indicating significant differences.

\section{Results}

3.1. Tlrs and Associated Factors Were Most Abundantly Expressed in Spleen from Healthy Trout. We performed a quantitative real-time PCR (RT-qPCR) profiling across 19 factors constituting the recognition of MAMPs in rainbow trout. Regarding the tissue-specific expression, we found that all 13 tlr genes were significantly expressed in spleen, head kidney, liver, and thymus (Figure 2(a)). However, we observed large differences in basal levels of $t l r$ transcripts. Spleen tissue featured the highest mRNA concentrations of almost all the Tlr-encoding genes, as frequently found in other fish species [26]. The copy numbers ranged from a minimum of $0.12 \pm 0.02 \times 10^{6}(t \operatorname{tr} 5)$ to a maximum of $1.3 \pm$ $0.18 \times 10^{6}$ copies $(t$ tr 21$)$ per $\mu \mathrm{g}$ RNA. The concentrations in head kidney amounted to approximately one-third of the values found in spleen with tlr5 featuring the lowest abundance of only $7 \%$ of the level in spleen. Levels in liver were generally much lower than in spleen, amounting for eleven of the considered $t l r$ genes on average to less than $10 \%$ of the levels as recorded in spleen. Yet, $t l r 5$ and $t l r 3$ were found to be exceptional since their mRNA concentrations reached $163 \%$ and $58 \%$ of those values measured in spleen.

We could not find distinctive tissue-specific expression profiles distinguishing the expression levels of the known transmembrane $t l r$ genes (e.g., tlr1, tlr2, and tlr5) from those of the known endosomal tlrs (tlr3, thr7, thr8a1, thr8a2, and tlr9) or of the fish-specific tlrs (tlr19, tlr20, tlr21, tlr22al, and tr22a2), the latter belonging all to the TLR11 family (Figure 1). Comparing the relative expression intensities between the various $t l r$ genes, we recorded the highest mRNA abundances $(>220,000$ transcripts/ $\mu \mathrm{g}$ RNA) for $t \operatorname{lr} 9$, $t \operatorname{lr} 20$, and trr21 in spleen, head kidney, and thymus, while tlr5 and tlr19 were found to be expressed on comparatively low levels in those tissues $(<160,000$ transcripts/ $\mu \mathrm{g}$ RNA).

Levels of nod 1 transcripts were recorded to monitor the expression of an alternative PRR [30]. Nod1 copy numbers were on similar levels as tlr2, trr9, and t tr20 in spleen and liver and exceeded in head kidney by more than twofold the level of the quite strongly transcribed $t / r 9$ or $t$ tr 21 .

Transcripts encoding downstream factors of the TLR pathway were also abundant (Figure 2(b)). Copy numbers of irak4a, irakl, traf6, and tollip genes were in a similar range as the tlr genes. Myd88, in contrast, exceeded by 3 - to 15 -fold the level of those other factors.

3.2. Severe Infection with A. salmonicida Strongly Induced illb, tnf, and il8. Rainbow trout were intraperitoneally infected with a high dosage $\left(1 \times 10^{7} \mathrm{cfu}\right)$ of $A$. salmonicida ensuring establishment of a uniform clinical infection in all individuals. At the end of the trail, infected trout displayed classical apathetic behavior; hemorrhages in liver; enlarged spleen and liver; and swollen intestine as typical symptoms of acute infection.

To characterize the course of the up-running immune defense after infection, we profiled the expression of several cytokine-encoding genes in our four target tissues spleen, head kidney, liver, and thymus. Illb [31, 32], Tnf [33], and Il8 $[34,35]$ play key roles during inflammation of rainbow trout. Il10 [36] and Tgfb [37] act as regulatory cytokines [38].

As early as $6 \mathrm{hpi}$, we found significantly elevated ils transcript levels $(p \leq 0.03)$ in liver (60-fold), spleen (28fold), and head kidney (27-fold) compared to naïve trout (Figure 3; Table 2). At $12 \mathrm{hpi}$, we recorded strongly increased illb mRNA abundances (with $p<0.01$ ) in head kidney (393-fold), liver (152-fold), spleen (48-fold), and thymus (10-fold) accompanied by moderately increased tnf mRNA levels (with $p<0.03$ ) in head kidney (12-fold), liver (12fold), and spleen (8-fold). At $72 \mathrm{hpi}$, we found a second, less 

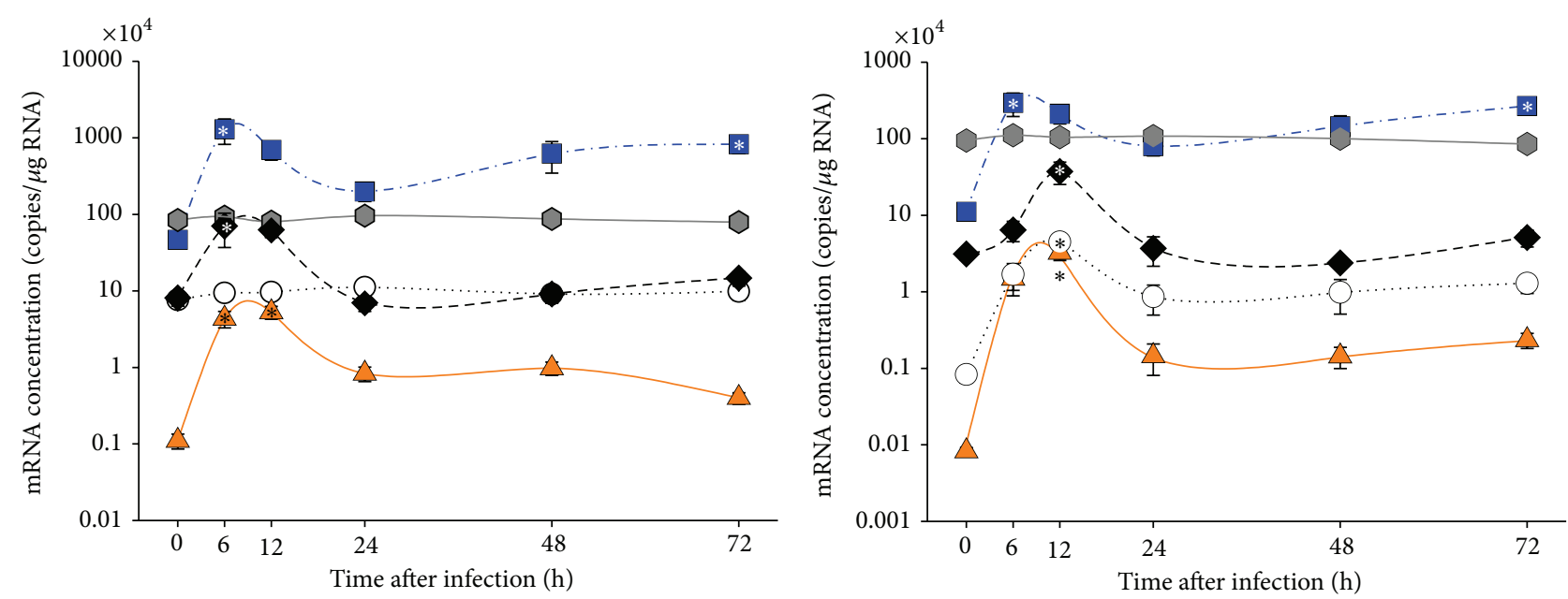
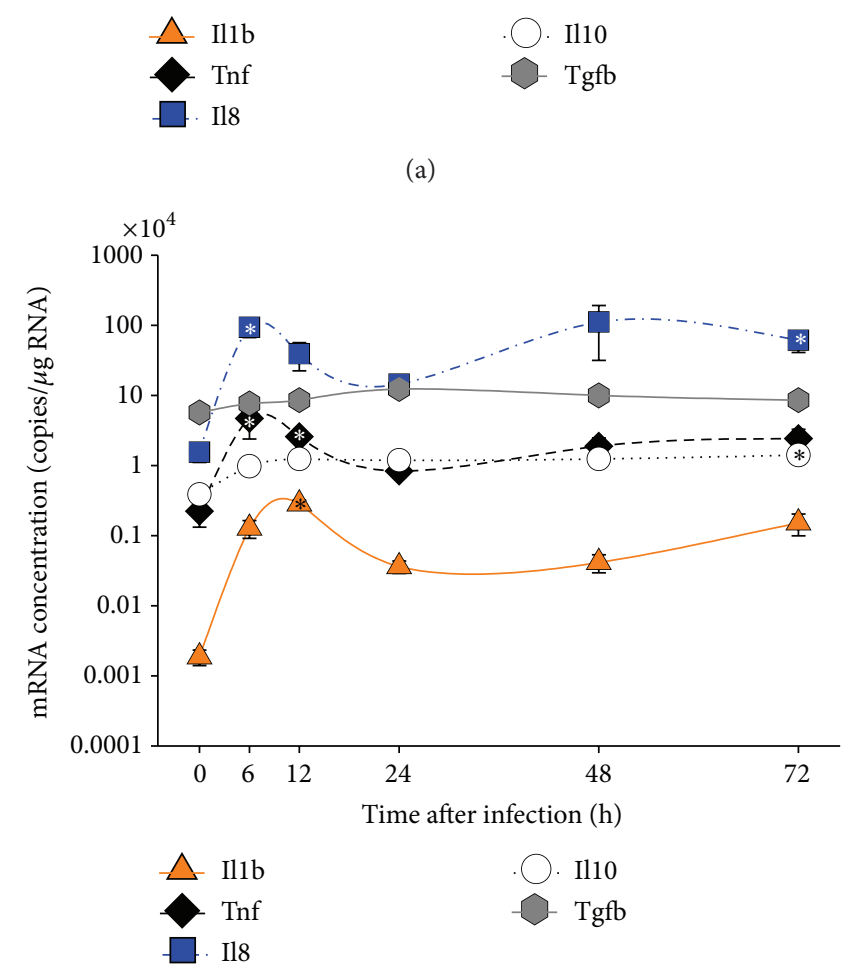

(c)

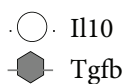

Tgfb

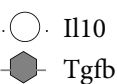

(b)

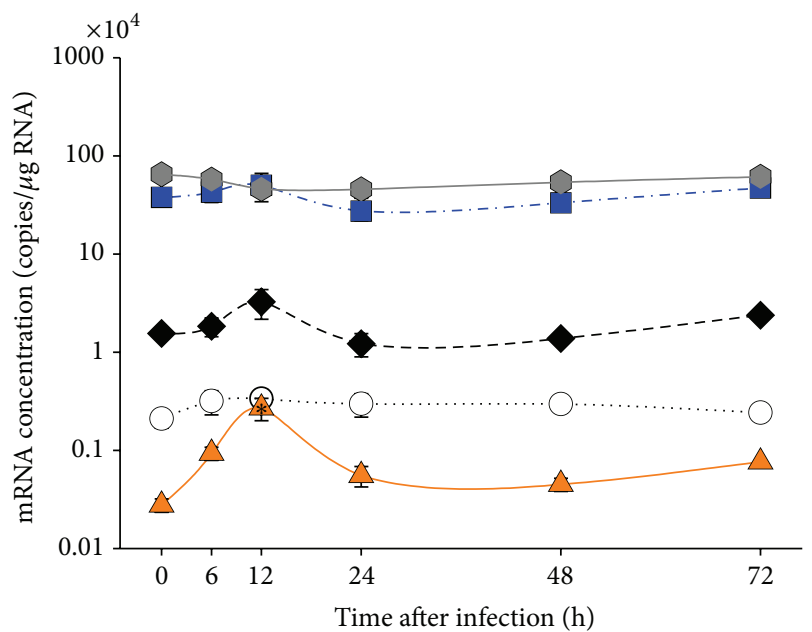

Il10
$-\mathrm{Tgfb}$

(d)

FIGURE 3: Relative levels of mRNAs encoding cytokines in selected immune organs of trout after infection with A. salmonicida. The relative number of mRNA copies (ordinate) encoding Illb (triangles; full line), Tnf (diamonds; broken line), Il8 (squares; line-dot-line), Il10 (circles; dotted line), and Tgfb (hexagon; full gray line) is plotted against the time after infection (abscissa). Different tissues (a) spleen, (b) head kidney, (c) liver, and (d) thymus were collected from five individuals/time point. Values are given as mean \pm SEM; the pertinent data are listed in Table 2. Note that the relative quantity is presented on a $\log 10$ scale. Asterisks indicate significant differences with $p<0.05$ compared to the control group $(0 \mathrm{~h})$.

pronounced upregulation of $i l 8$ gene expression (with $p<$ 0.02 ) in liver (39-fold), head kidney (24-fold), and spleen (18-fold). Il10 expression was highly upregulated in head kidney at $12 \mathrm{hpi}$ (54-fold) indicating the onset of immunedampening mechanisms restricting inflammation. Only tgfb gene remained on a similar expression level throughout the infection.

These data together validate that the severe infection initiated strong inflammation.
3.3. Marginal Regulation of Factors Constituting the TLR Signaling Cascade during Severe Aeromonas salmonicida Infection. A key aspect of our study was to profile the expression of all our candidate Tlr factors during A. salmonicida infection identifying prominently regulated members of this receptor family. The data are visualized in Figure 4 and listed in Table 3(a). Surprisingly, from the 13 tlr genes studied, only the expression of tlr22a2 was clearly and quickly induced in head kidney (6hpi: 6-fold; 12 hpi: 4-fold over controls) and liver 
TABLE 2: Expression profiles of various cytokines in selected tissues of rainbow trout at different time points after infection.

\begin{tabular}{|c|c|c|c|c|c|c|}
\hline \multirow{2}{*}{ Gene symbol } & \multirow{2}{*}{ Tissues } & \multicolumn{5}{|c|}{ Fold change values at time points after infection relative to control } \\
\hline & & $6 \mathrm{~h}$ & $12 \mathrm{~h}$ & $24 \mathrm{~h}$ & $48 \mathrm{~h}$ & $72 \mathrm{~h}$ \\
\hline \multirow{4}{*}{$i l 1 b$} & Spleen & $39.35 \pm 12.98^{*}$ & $47.80 \pm 13.94^{*}$ & $7.54 \pm 2.33$ & $8.89 \pm 2.64$ & $3.63 \pm 1.04$ \\
\hline & Head kidney & $180.12 \pm 75.62$ & $393.18 \pm 95.32^{*}$ & $17.50 \pm 7.97$ & $17.39 \pm 5.72$ & $28.38 \pm 8.11$ \\
\hline & Liver & $68.47 \pm 26.01$ & $151.60 \pm 42.63^{*}$ & $19.35 \pm 6.24$ & $22.21 \pm 8.50$ & $81.23 \pm 32.69$ \\
\hline & Thymus & $3.36 \pm 0.73$ & $9.74 \pm 2.93^{*}$ & $2.00 \pm 0.57$ & $1.63 \pm 0.35$ & $2.75 \pm 0.66$ \\
\hline \multirow{4}{*}{$\operatorname{tnf}$} & Spleen & $8.68 \pm 4.55$ & $7.76 \pm 2.34^{*}$ & $-1.16 \pm 0.37$ & $1.12 \pm 0.30$ & $1.82 \pm 0.52$ \\
\hline & Head kidney & $2.06 \pm 0.70$ & $11.94 \pm 4.32^{*}$ & $-1.18 \pm 0.53$ & $-1.31 \pm 0.26$ & $1.64 \pm 0.38$ \\
\hline & Liver & $21.10 \pm 13.46^{*}$ & $11.58 \pm 4.93^{*}$ & $3.74 \pm 1.68$ & $8.50 \pm 4.33$ & $10.88 \pm 5.68$ \\
\hline & Thymus & $1.18 \pm 0.28$ & $2.10 \pm 0.74$ & $-1.27 \pm 0.36$ & $-1.13 \pm 0.15$ & $1.54 \pm 0.25$ \\
\hline \multirow{4}{*}{ ils } & Spleen & $27.85 \pm 11.11^{*}$ & $14.92 \pm 4.55$ & $4.30 \pm 1.31$ & $13.37 \pm 6.27$ & $17.80 \pm 6.48^{*}$ \\
\hline & Head kidney & $26.59 \pm 9.13^{*}$ & $19.11 \pm 5.15$ & $7.24 \pm 1.89$ & $13.14 \pm 4.92$ & $24.12 \pm 7.00^{*}$ \\
\hline & Liver & $\mathbf{6 0 . 1 4} \pm 24.25^{*}$ & $25.32 \pm 13.09$ & $9.30 \pm 3.11$ & $71.70 \pm 55.32$ & $39.32 \pm 22.19^{*}$ \\
\hline & Thymus & $1.13 \pm 0.31$ & $1.33 \pm 0.48$ & $-1.38 \pm 0.35$ & $-1.14 \pm 0.52$ & $1.25 \pm 0.28$ \\
\hline \multirow{4}{*}{ il10 } & Spleen & $1.24 \pm 0.33$ & $1.26 \pm 0.27$ & $1.46 \pm 0.41$ & $1.19 \pm 0.35$ & $1.29 \pm 0.38$ \\
\hline & Head kidney & $20.39 \pm 9.00$ & $\mathbf{5 4 . 0 4} \pm 18.64^{*}$ & $10.35 \pm 4.94$ & $11.83 \pm 6.24$ & $15.53 \pm 6.49$ \\
\hline & Liver & $2.52 \pm 0.88$ & $3.19 \pm 1.12$ & $3.08 \pm 0.84$ & $3.20 \pm 0.95$ & $3.63 \pm 1.14^{*}$ \\
\hline & Thymus & $1.51 \pm 0.52$ & $1.59 \pm 0.50$ & $1.41 \pm 0.47$ & $1.41 \pm 0.38$ & $1.15 \pm 0.32$ \\
\hline \multirow{4}{*}{$\operatorname{tg} f b$} & Spleen & $1.11 \pm 0.08$ & $-1.05 \pm 0.09$ & $1.14 \pm 0.15$ & $1.04 \pm 0.11$ & $-1.06 \pm 0.12$ \\
\hline & Head kidney & $1.17 \pm 0.12$ & $1.10 \pm 0.09$ & $1.14 \pm 0.12$ & $1.06 \pm 0.14$ & $-1.11 \pm 0.13$ \\
\hline & Liver & $1.34 \pm 0.14$ & $1.50 \pm 0.18$ & $2.17 \pm 0.35^{*}$ & $1.76 \pm 0.24$ & $1.50 \pm 0.20$ \\
\hline & Thymus & $-1.13 \pm 0.16$ & $-1.40 \pm 0.22$ & $-1.42 \pm 0.33$ & $-1.21 \pm 0.24$ & $-1.06 \pm 0.16$ \\
\hline
\end{tabular}

${ }^{*}$ Significant expression difference $(p<0.05)$ between the infected and the control groups is indicated in bold.

(12 and 48 hpi: 4 -fold over controls) in the infected trout. The genes encoding Tlr9, -19, and -20 were induced in liver to a low extent (2- to 3-fold; $p<0.05$ ). Transcript levels of $t / r 1$ and trr22al remained stable over time and those encoding Tlr2, $-3,-5,-7,-8 \mathrm{a} 1,-8 \mathrm{a} 2,-9,-21$, and Nod1 were even downregulated $(<4$-fold) in spleen or head kidney.

No downregulation was found for any of our candidate downstream factors of TLR signaling in any of the four tissues (Figure 4; Table 3(b)). Levels of all these factors remained virtually stable in thymus during the entire infection period. In contrast, all these factors were significantly upregulated in liver, at least at some time point during infection. The mRNA concentration of myd88 was most prominently upregulated (>6-fold, 12 hpi and $72 \mathrm{hpi}$ ) and remained on elevated levels throughout. The traf6 mRNA concentration rose at $12 \mathrm{hpi}$ to a subsequently sustained 2-fold increased level. The mRNA concentration of tollip was raised at $24 \mathrm{hpi}$ by $\sim 3$-fold and increased further until $72 \mathrm{hpi}$. The induction profile of irakl was remarkable in so far as it significantly increased $>2$ fold in three organs, spleen, head kidney, and liver already 6 hpi. This elevated level was sustained in liver throughout the infection period ( $p>0.05$ at 24 and $48 \mathrm{hpi}$ ), while it clearly dropped down later compared to $12 \mathrm{hpi}$ in spleen and head kidney.

3.4. Infection Quickly Induced an Influx Mainly of Myeloid Cells into the Peritoneum. Activation of the early cellular immune response in the peritoneal cavity, the site of infection, was indicated by a very strong increase in the total number of cells (Figure 5(a)). The number of peritoneal leukocytes increased during the first 12 hpi by $>40$-fold $(p<0.05)$. Their number remained on this high level for another $60 \mathrm{~h}$ in all infected fish. Only slight and statistically insignificant changes were observed in the control group injected with PBS ( $<2$-fold, $p=0.6$ ).

Flow cytometry was used to differentiate myeloid from lymphoid cells in peritoneal lavages (Figures 5(b) and 5(c)). Myeloid cells (mainly monocytes/macrophages and granulocytes) were the first to become massively recruited. Their number increased already during the first 6 hpi by 43 -fold $(p<0.05)$ and reached a plateau level of a 162-fold $(p<$ 0.01 ) increase at $12 \mathrm{hpi}$ (Figure 5(b)). Significant amounts of lymphoid cells (most likely B cells; maybe T cells; natural killer-like cells) were also recruited into the peritoneum, but with a slower, yet steady rate. Their number was increased by 41 -fold $(p<0.02)$ at $72 \mathrm{hpi}$. The different rates for recruiting both cell types eventually resulted in a grossly altered composition of the peritoneal cell population. The relative proportion of myeloid (44\%) and lymphoid cells (55\%) was quite balanced in control trout (Figure 5(c)). The A. salmonicida infection changed the situation tremendously. Myeloid cells constituted more than $80 \%$ of the peritoneal cells already at $6 \mathrm{hpi}$, whereas lymphoid cells accounted for only $18 \%$. This ratio remained almost constant until 72 hpi. PBS injection provoked only mild fluctuations of this ratio.

The data show that infection activated very swiftly the cellular branch of innate immune defense by recruiting wellknown effector cells and this occurred concomitantly and 


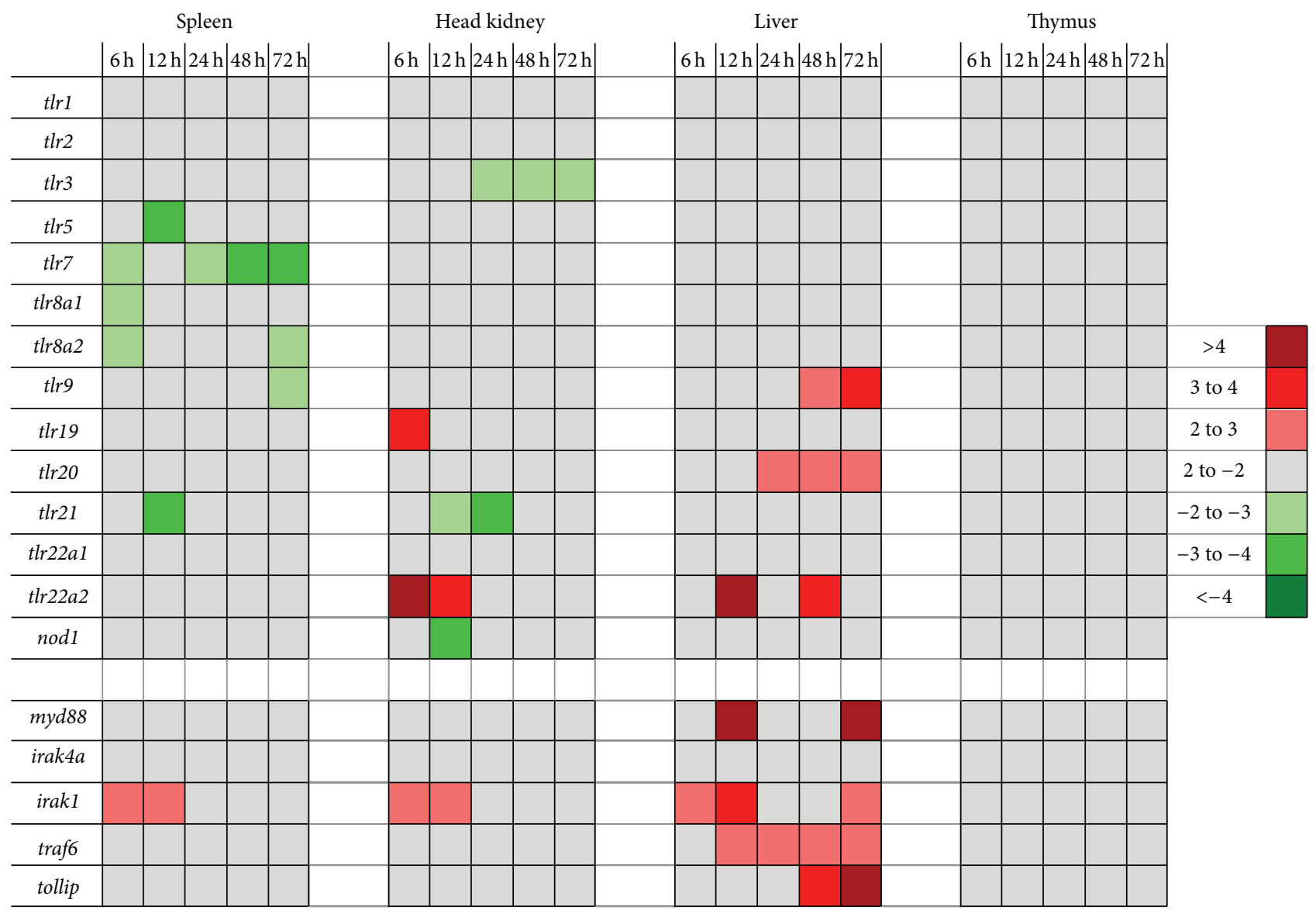

FIGURE 4: Modulation of the mRNA concentration of factors contributing to TLR signaling during infection. Colored fields represent significantly $(p<0.05)$ altered fold changes $(>2$-fold) of the mRNA concentrations as measured in the respective organs at the various times after infection. The pertinent data are listed in Tables 3(a) and 3(b).

was conceivably triggered by the induced expression of key cytokines.

3.5. Significant Cell Migration of $T$ and B Cells Is Likely to Occur in Head Kidney from $12 \mathrm{hpi}$ Onwards. We profiled the dynamics of lymphoid cell migration in the four immune organs in order to validate the onset of adaptive immune activities involving $\mathrm{T}$ and $\mathrm{B}$ cells. T cell receptor $\beta(\operatorname{trb})$ and immunoglobulin $\mathrm{M}$, heavy chain (ighm) are broadly used gene markers indicating the presence of cells of the T- or Btype lineage [39]. We found only in the head kidney clear and significant changes of these markers $(p=0.03)$. The trb level remained stable for $12 \mathrm{hpi}$ and subsequently rose to reach its maximum 12 -fold increase at $72 \mathrm{hpi}$. Concomitantly, the ighm level dropped steeply after $12 \mathrm{hpi}$ and reached a lower level plateau (11-fold reduction) at $24 \mathrm{hpi}$ (Figure 6). This observation indicates either that $\mathrm{B}$ cells emigrated from the head kidney or that $\mathrm{T}$ or myeloid cells immigrated into this organ or that lymphocytes were strongly induced to proliferate here, thereby affecting the proportion of immune cells.

Changes of trb and ighm levels were all less than 3-fold and mostly statistically insignificant in the other three organs (thymus, spleen, and liver; Table 4).

\section{Discussion}

Toll-like receptors are key components of the innate immune system promoting a proinflammatory state after invasion of pathogens. Analyzing the tissue-specific and immunemodulated expression of a comprehensive set of factors contributing to TLR signal transduction may therefore inform about their role to overcome microbial threats (see [26] for a review). RT-qPCR is often the method of choice for the analysis due to the lack of fish-specific antibodies [26] and its superior sensitivity [40]. Moreover, a significant and positive correlation between the concentration of mRNA and its encoded protein has been found for a vast number of genes [41] and also for $t l r$ genes in fish [42].

The prime interest of our study was to analyze in trout the role of TLR signaling to combat infection with the Gramnegative pathogen A. salmonicida, since no Tlr is known in teleost fish to recognize LPS, the major component of the outer cell wall of this pathogen. Prominent feature of our comprehensive survey of tlr expression during infection was that their expression was only moderately regulated, if at all. We conclude from this observation that $A$. salmonicida infection strongly induced proinflammatory mechanisms but failed to induce those pathways controlling the expression of 
TABLE 3: (a) Expression profiles of various PRRs in selected tissues of rainbow trout at different time points after infection. (b) Expression profiles of various downstream factors in selected tissues of rainbow trout at different time points after infection.

(a)

\begin{tabular}{|c|c|c|c|c|c|c|}
\hline \multirow{2}{*}{ Gene symbol } & \multirow{2}{*}{ Tissues } & \multicolumn{5}{|c|}{ Fold change values at time points after infection relative to control } \\
\hline & & $6 \mathrm{~h}$ & $12 \mathrm{~h}$ & $24 \mathrm{~h}$ & $48 \mathrm{~h}$ & $72 \mathrm{~h}$ \\
\hline \multirow{4}{*}{ tlr1 } & Spleen & $-1.07 \pm 0.19$ & $-1.02 \pm 0.23$ & $1.07 \pm 0.16$ & $-1.07 \pm 0.18$ & $-1.54 \pm 0.28$ \\
\hline & Head kidney & $1.61 \pm 0.18$ & $1.72 \pm 0.25$ & $1.50 \pm 0.27$ & $1.57 \pm 0.21$ & $1.66 \pm 0.13$ \\
\hline & Liver & $-1.11 \pm 0.18$ & $1.72 \pm 0.31$ & $2.32 \pm 0.56$ & $1.67 \pm 0.31$ & $1.70 \pm 0.22$ \\
\hline & Thymus & $-1.31 \pm 0.29$ & $-1.20 \pm 0.32$ & $1.21 \pm 0.29$ & $1.13 \pm 0.24$ & $1.09 \pm 0.20$ \\
\hline \multirow{4}{*}{ tlr2 } & Spleen & $-1.13 \pm 0.16$ & $-1.73 \pm 0.33^{*}$ & $-1.86 \pm 0.41^{*}$ & $-1.46 \pm 0.15$ & $-1.68 \pm 0.20^{*}$ \\
\hline & Head kidney & $1.24 \pm 0.19$ & $-1.13 \pm 0.17$ & $-1.68 \pm 0.28$ & $-1.10 \pm 0.22$ & $-1.18 \pm 0.15$ \\
\hline & Liver & $-1.01 \pm 0.11$ & $-1.11 \pm 0.11$ & $-1.01 \pm 0.12$ & $1.50 \pm 0.32$ & $1.16 \pm 0.18$ \\
\hline & Thymus & $-1.12 \pm 0.21$ & $-1.07 \pm 0.19$ & $-1.07 \pm 0.25$ & $1.16 \pm 0.19$ & $1.22 \pm 0.16$ \\
\hline \multirow{4}{*}{ tlr3 } & Spleen & $-1.58 \pm 0.17$ & $-1.67 \pm 0.25$ & $-1.21 \pm 0.25$ & $-1.82 \pm 0.23^{*}$ & $-1.70 \pm 0.23^{*}$ \\
\hline & Head kidney & $-1.52 \pm 0.17^{*}$ & $-1.99 \pm 0.26^{*}$ & $-2.49 \pm 0.30^{*}$ & $-2.08 \pm 0.29^{*}$ & $-2.09 \pm 0.32^{*}$ \\
\hline & Liver & $-1.21 \pm 0.31$ & $-1.64 \pm 0.39$ & $-1.40 \pm 0.36$ & $-1.83 \pm 0.47$ & $-1.64 \pm 0.51$ \\
\hline & Thymus & $-1.26 \pm 0.27$ & $-1.87 \pm 0.49$ & $-1.46 \pm 0.37$ & $-1.52 \pm 0.37$ & $-1.63 \pm 0.34$ \\
\hline \multirow{4}{*}{ tlr5 } & Spleen & $-2.77 \pm 0.71$ & $-3.88 \pm 0.71^{*}$ & $-2.76 \pm 0.70$ & $-2.34 \pm 0.66$ & $-1.61 \pm 0.49$ \\
\hline & Head kidney & $-1.07 \pm 0.27$ & $1.03 \pm 0.64$ & $-2.33 \pm 0.48$ & $-1.62 \pm 0.47$ & $-1.55 \pm 0.34$ \\
\hline & Liver & $1.28 \pm 0.31$ & $-1.30 \pm 0.25$ & $1.77 \pm 0.37$ & $1.99 \pm 0.37$ & $1.96 \pm 0.38$ \\
\hline & Thymus & $1.14 \pm 0.23$ & $-1.12 \pm 0.29$ & $-2.08 \pm 0.35$ & $-1.29 \pm 0.30$ & $-1.91 \pm 0.52$ \\
\hline \multirow{4}{*}{$\operatorname{tlr} 7$} & Spleen & $-2.10 \pm 0.24^{*}$ & $-1.62 \pm 0.58$ & $-2.79 \pm 0.48^{*}$ & $-3.23 \pm 0.62^{*}$ & $-3.40 \pm 0.85^{*}$ \\
\hline & Head kidney & $1.95 \pm 0.45$ & $2.22 \pm 0.63$ & $1.51 \pm 0.49$ & $-1.28 \pm 0.35$ & $-1.04 \pm 0.24$ \\
\hline & Liver & $-1.01 \pm 0.23$ & $1.06 \pm 0.19$ & $1.17 \pm 0.20$ & $1.33 \pm 0.41$ & $-1.05 \pm 0.30$ \\
\hline & Thymus & $-1.30 \pm 0.28$ & $-1.34 \pm 0.33$ & $-1.03 \pm 0.40$ & $-1.35 \pm 0.28$ & $-1.47 \pm 0.31$ \\
\hline \multirow{4}{*}{ tlr8a1 } & Spleen & $-\mathbf{2 . 0 3} \pm 0.29^{*}$ & $-1.76 \pm 0.28^{*}$ & $-1.29 \pm 0.20$ & $-1.36 \pm 0.23$ & $-1.62 \pm 0.29^{*}$ \\
\hline & Head kidney & $-1.35 \pm 0.22$ & $-1.89 \pm 0.39$ & $-1.90 \pm 0.34$ & $-1.30 \pm 0.45$ & $-1.89 \pm 0.77$ \\
\hline & Liver & $1.47 \pm 0.41$ & $1.81 \pm 0.42$ & $2.86 \pm 0.77$ & $2.88 \pm 1.00$ & $1.67 \pm 0.43$ \\
\hline & Thymus & $1.02 \pm 0.21$ & $-1.01 \pm 0.27$ & $-1.09 \pm 0.28$ & $1.15 \pm 0.28$ & $-1.41 \pm 0.30$ \\
\hline \multirow{4}{*}{ tlr8a2 } & Spleen & $-2.45 \pm 0.53^{*}$ & $-1.99 \pm 0.29^{*}$ & $-1.49 \pm 0.27$ & $-\mathbf{1 . 8 5} \pm 0.32^{*}$ & $-2.75 \pm 0.45^{*}$ \\
\hline & Head kidney & $-1.31 \pm 0.43$ & $-1.46 \pm 0.31$ & $-1.23 \pm 0.24$ & $-1.29 \pm 0.27$ & $-1.91 \pm 0.31$ \\
\hline & Liver & $1.54 \pm 0.50$ & $1.75 \pm 0.56$ & $2.30 \pm 0.56$ & $2.56 \pm 0.81$ & $1.54 \pm 0.42$ \\
\hline & Thymus & $1.07 \pm 0.27$ & $-1.49 \pm 0.33$ & $-1.27 \pm 0.32$ & $1.03 \pm 0.45$ & $-1.28 \pm 0.47$ \\
\hline \multirow{4}{*}{$\operatorname{tlr} 9$} & Spleen & $1.09 \pm 0.11$ & $1.32 \pm 0.11$ & $1.44 \pm 0.17$ & $1.20 \pm 0.22$ & $-\mathbf{2 . 0 0} \pm 0.25^{*}$ \\
\hline & Head kidney & $1.33 \pm 0.19$ & $1.35 \pm 0.25$ & $1.24 \pm 0.21$ & $1.29 \pm 0.18$ & $1.43 \pm 0.17$ \\
\hline & Liver & $1.50 \pm 0.22$ & $1.95 \pm 0.32$ & $2.57 \pm 0.42$ & $2.87 \pm 0.52^{*}$ & $3.44 \pm 0.51^{*}$ \\
\hline & Thymus & $-1.22 \pm 0.37$ & $-1.20 \pm 0.40$ & $1.15 \pm 0.26$ & $1.20 \pm 0.39$ & $1.33 \pm 0.42$ \\
\hline \multirow{4}{*}{ tlr19 } & Spleen & $-1.22 \pm 0.28$ & $-1.66 \pm 0.59$ & $-1.62 \pm 0.46$ & $1.45 \pm 0.38$ & $-2.82 \pm 0.66$ \\
\hline & Head kidney & $3.18 \pm 0.84^{*}$ & $2.52 \pm 0.54$ & $2.73 \pm 0.85$ & $2.19 \pm 0.64$ & $2.00 \pm 0.55$ \\
\hline & Liver & $2.83 \pm 1.53$ & $-1.82 \pm 0.59$ & $1.00 \pm 0.23$ & $-1.90 \pm 0.54$ & $-2.00 \pm 0.57$ \\
\hline & Thymus & $1.06 \pm 0.39$ & $-1.22 \pm 0.37$ & $1.35 \pm 0.55$ & $1.02 \pm 0.30$ & $1.42 \pm 0.43$ \\
\hline \multirow{4}{*}{$\operatorname{tlr} 20$} & Spleen & $-1.58 \pm 0.29$ & $-1.71 \pm 0.38$ & $-1.23 \pm 0.21$ & $1.08 \pm 0.27$ & $-1.02 \pm 0.25$ \\
\hline & Head kidney & $1.29 \pm 0.20$ & $-1.40 \pm 0.21$ & $1.07 \pm 0.17$ & $1.24 \pm 0.18$ & $1.49 \pm 0.21$ \\
\hline & Liver & $1.55 \pm 0.23$ & $1.74 \pm 0.20$ & $2.01 \pm 0.19^{*}$ & $2.20 \pm 0.25^{*}$ & $2.02 \pm 0.26^{*}$ \\
\hline & Thymus & $-1.17 \pm 0.24$ & $1.32 \pm 0.35$ & $-1.22 \pm 0.32$ & $1.19 \pm 0.26$ & $1.42 \pm 0.31$ \\
\hline \multirow{4}{*}{$\operatorname{tlr} 21$} & Spleen & $-1.39 \pm 0.28$ & $-3.82 \pm 0.46^{*}$ & $-1.83 \pm 0.40$ & $-1.25 \pm 0.35$ & $-1.03 \pm 0.19$ \\
\hline & Head kidney & $-1.06 \pm 0.26$ & $-2.96 \pm 0.61^{*}$ & $-3.36 \pm 0.51^{*}$ & $-1.65 \pm 0.26$ & $-1.52 \pm 0.24$ \\
\hline & Liver & $1.67 \pm 0.48$ & $1.61 \pm 0.44$ & $1.34 \pm 0.21$ & $2.16 \pm 0.58$ & $1.51 \pm 0.34$ \\
\hline & Thymus & $1.07 \pm 0.18$ & $-1.31 \pm 0.26$ & $-1.47 \pm 0.29$ & $1.00 \pm 0.21$ & $-1.13 \pm 0.21$ \\
\hline \multirow{4}{*}{$\operatorname{tlr} 22 a 1$} & Spleen & $1.21 \pm 0.27$ & $-1.18 \pm 0.22$ & $-1.10 \pm 0.23$ & $1.01 \pm 0.27$ & $-1.99 \pm 0.45$ \\
\hline & Head kidney & $1.55 \pm 0.50$ & $1.41 \pm 0.34$ & $1.51 \pm 0.56$ & $1.06 \pm 0.24$ & $-1.75 \pm 0.44$ \\
\hline & Liver & $2.12 \pm 0.52$ & $1.94 \pm 0.43$ & $2.50 \pm 0.58$ & $3.23 \pm 1.00$ & $1.41 \pm 0.34$ \\
\hline & Thymus & $1.24 \pm 0.21$ & $-1.11 \pm 0.29$ & $1.11 \pm 0.35$ & $1.07 \pm 0.23$ & $-1.46 \pm 0.23$ \\
\hline
\end{tabular}


(a) Continued.

\begin{tabular}{|c|c|c|c|c|c|c|}
\hline \multirow{2}{*}{ Gene symbol } & \multirow{2}{*}{ Tissues } & \multicolumn{5}{|c|}{ Fold change values at time points after infection relative to control } \\
\hline & & $6 \mathrm{~h}$ & $12 \mathrm{~h}$ & $24 \mathrm{~h}$ & $48 \mathrm{~h}$ & $72 \mathrm{~h}$ \\
\hline \multirow{4}{*}{$\operatorname{tlr} 22 a 2$} & Spleen & $3.02 \pm 0.64$ & $1.21 \pm 0.24$ & $1.11 \pm 0.11$ & $1.89 \pm 0.39$ & $1.53 \pm 0.30$ \\
\hline & Head kidney & $6.14 \pm 2.37^{*}$ & $3.81 \pm 0.70^{*}$ & $1.63 \pm 0.32$ & $3.27 \pm 0.70$ & $2.71 \pm 0.48$ \\
\hline & Liver & $3.51 \pm 0.79$ & $4.41 \pm 0.97^{*}$ & $2.94 \pm 0.85$ & $3.85 \pm 0.97^{*}$ & $3.12 \pm 0.80$ \\
\hline & Thymus & $1.37 \pm 0.25$ & $1.83 \pm 0.33$ & $1.48 \pm 0.40$ & $1.23 \pm 0.34$ & $1.15 \pm 0.28$ \\
\hline \multirow{4}{*}{ nod 1} & Spleen & $-1.05 \pm 0.15$ & $-1.60 \pm 0.20$ & $-1.01 \pm 0.14$ & $1.07 \pm 0.12$ & $-1.13 \pm 0.13$ \\
\hline & Head kidney & $-1.22 \pm 0.23$ & $-3.08 \pm 0.61^{*}$ & $-1.60 \pm 0.26$ & $-1.31 \pm 0.32$ & $-1.59 \pm 0.35$ \\
\hline & Liver & $1.20 \pm 0.18$ & $1.26 \pm 0.19$ & $1.37 \pm 0.19$ & $1.36 \pm 0.30$ & $1.74 \pm 0.34$ \\
\hline & Thymus & $-1.02 \pm 0.21$ & $1.45 \pm 0.33$ & $1.35 \pm 0.39$ & $-1.04 \pm 0.27$ & $-1.15 \pm 0.26$ \\
\hline
\end{tabular}

${ }^{*}$ Significant expression difference $(p<0.05)$ between the infected and the control groups is indicated in bold.

(b)

\begin{tabular}{|c|c|c|c|c|c|c|}
\hline \multirow{2}{*}{ Gene symbol } & \multirow{2}{*}{ Tissues } & \multicolumn{5}{|c|}{ Fold change values of infected group relative to the control } \\
\hline & & $6 \mathrm{~h}$ & $12 \mathrm{~h}$ & $24 \mathrm{~h}$ & $48 \mathrm{~h}$ & $72 \mathrm{~h}$ \\
\hline \multirow{4}{*}{ myd88 } & Spleen & $1.44 \pm 0.25$ & $1.68 \pm 0.24$ & $1.33 \pm 0.33$ & $1.36 \pm 0.22$ & $1.25 \pm 0.20$ \\
\hline & Head kidney & $1.37 \pm 0.16$ & $1.33 \pm 0.20$ & $1.22 \pm 0.22$ & $1.45 \pm 0.29$ & $1.04 \pm 0.12$ \\
\hline & Liver & $2.75 \pm 0.48$ & $6.68 \pm 0.63^{*}$ & $3.34 \pm 0.76$ & $4.37 \pm 1.48$ & $6.78 \pm 1.89^{*}$ \\
\hline & Thymus & $1.08 \pm 0.14$ & $-1.13 \pm 0.23$ & $1.01 \pm 0.21$ & $1.09 \pm 0.17$ & $1.00 \pm 0.14$ \\
\hline \multirow{4}{*}{ irak4a } & Spleen & $-1.02 \pm 0.14$ & $-1.20 \pm 0.10$ & $1.26 \pm 0.09$ & $1.03 \pm 0.16$ & $-1.06 \pm 0.14$ \\
\hline & Head kidney & $1.04 \pm 0.11$ & $-1.25 \pm 0.16$ & $-1.36 \pm 0.19$ & $-1.31 \pm 0.18$ & $-1.39 \pm 0.19$ \\
\hline & Liver & $1.38 \pm 0.14$ & $1.67 \pm 0.14$ & $1.87 \pm 0.24^{*}$ & $1.51 \pm 0.15$ & $1.86 \pm 0.23^{*}$ \\
\hline & Thymus & $1.17 \pm 0.16$ & $1.10 \pm 0.18$ & $1.08 \pm 0.18$ & $1.26 \pm 0.17$ & $1.71 \pm 0.23^{*}$ \\
\hline \multirow{4}{*}{ irak1 } & Spleen & $2.81 \pm 0.43^{*}$ & $2.86 \pm 0.24^{*}$ & $1.56 \pm 0.17$ & $1.51 \pm 0.22$ & $1.13 \pm 0.20$ \\
\hline & Head kidney & $2.24 \pm 0.35^{*}$ & $2.54 \pm 0.47^{*}$ & $1.23 \pm 0.15$ & $1.34 \pm 0.17$ & $1.55 \pm 0.18$ \\
\hline & Liver & $2.60 \pm 0.50^{*}$ & $3.93 \pm 0.49^{*}$ & $2.12 \pm 0.35$ & $2.14 \pm 0.30$ & $2.34 \pm 0.34^{*}$ \\
\hline & Thymus & $1.11 \pm 0.13$ & $-1.07 \pm 0.19$ & $-1.25 \pm 0.21$ & $-1.14 \pm 0.16$ & $1.13 \pm 0.15$ \\
\hline \multirow{4}{*}{ traf6 } & Spleen & $1.10 \pm 0.15$ & $1.29 \pm 0.13$ & $1.26 \pm 0.13$ & $1.21 \pm 0.16$ & $1.15 \pm 0.13$ \\
\hline & Head kidney & $1.05 \pm 0.09$ & $1.49 \pm 0.15$ & $1.36 \pm 0.14$ & $1.57 \pm 0.15^{*}$ & $1.37 \pm 0.15$ \\
\hline & Liver & $1.27 \pm 0.09$ & $2.21 \pm 0.27^{*}$ & $2.21 \pm 0.30^{*}$ & $2.04 \pm 0.33^{*}$ & $2.17 \pm 0.25^{*}$ \\
\hline & Thymus & $1.18 \pm 0.15$ & $-1.04 \pm 0.11$ & $-1.01 \pm 0.15$ & $-1.03 \pm 0.13$ & $1.78 \pm 0.22^{*}$ \\
\hline \multirow{4}{*}{ tollip } & Spleen & $1.06 \pm 0.19$ & $1.21 \pm 0.21$ & $1.29 \pm 0.22$ & $1.15 \pm 0.23$ & $1.24 \pm 0.21$ \\
\hline & Head kidney & $1.31 \pm 0.21$ & $-1.05 \pm 0.24$ & $1.14 \pm 0.12$ & $1.27 \pm 0.14$ & $1.11 \pm 0.10$ \\
\hline & Liver & $1.62 \pm 0.48$ & $1.73 \pm 0.54$ & $2.74 \pm 0.87$ & $3.44 \pm 1.14^{*}$ & $4.53 \pm 1.43^{*}$ \\
\hline & Thymus & $1.03 \pm 0.15$ & $-1.11 \pm 0.29$ & $1.05 \pm 0.24$ & $-1.04 \pm 0.19$ & $1.29 \pm 0.26$ \\
\hline
\end{tabular}

* Significant expression difference $(p<0.05)$ between the infected and the control groups is indicated in bold.

genes encoding TLRs and associated factors. TLR expression is known to be regulated by the JAK/STAT signaling cascade [43] and hence our data hint, by inference, that also the latter signaling cascade was not largely activated by the infection. Beyond that, such comparatively small modulations in the levels of $t r$ transcripts cannot unequivocally be attributed to altered gene expression since they might as well reflect altered cell composition in the respective organs due to cell migration during the up-running immune defense. For example, large differences have recently been reported regarding the organspecific content of $t l r$-expressing $\operatorname{IgM}^{+}$cells in trout [44].

This general pattern of only a moderate regulation of $t$ r expression during infection in $O$. mykiss contrasts reports from other organisms. Pronounced upregulation of $t \mathrm{tr}$ expression after infection with relevant pathogens has been documented for mammals [21,23], invertebrates [45, 46], and also bony fish. Distinct sets of tlr genes showed enhanced expression in channel catfish Ictalurus punctatus [19], Atlantic salmon Salmo salar [18], and Antarctic bullhead notothen Notothenia coriiceps [20] after parasitic, bacterial, and viral infection, respectively. After infection, some of those $t r$ genes revealed distinctively high mRNA abundances with changes of more than 10-fold above controls.

4.1. Tlr22a2 Was the Most Conspicuously Regulated tlr but Is Conceivably Not Specific for A. salmonicida Recognition. Tlr22 is important for induced cytokine synthesis [17]. The unique and quick sixfold upregulation of tr $22 a 2$ already 6 hpi in head kidney would highlight this TLR as a candidate for specifically contributing to $A$. salmonicida recognition. Yet, attributing that specific role to this factor is highly unlikely since the expression of the fish-specific tlr22 is known to be 


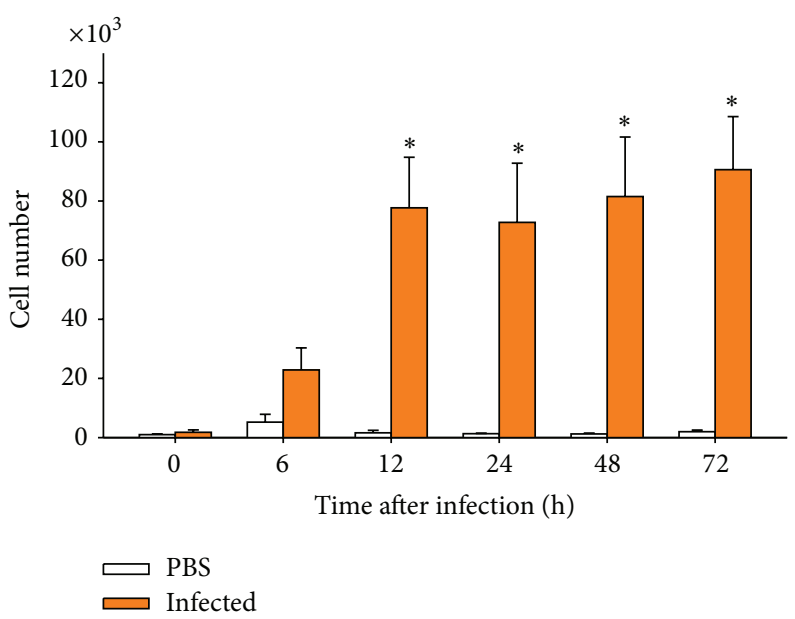

(a)

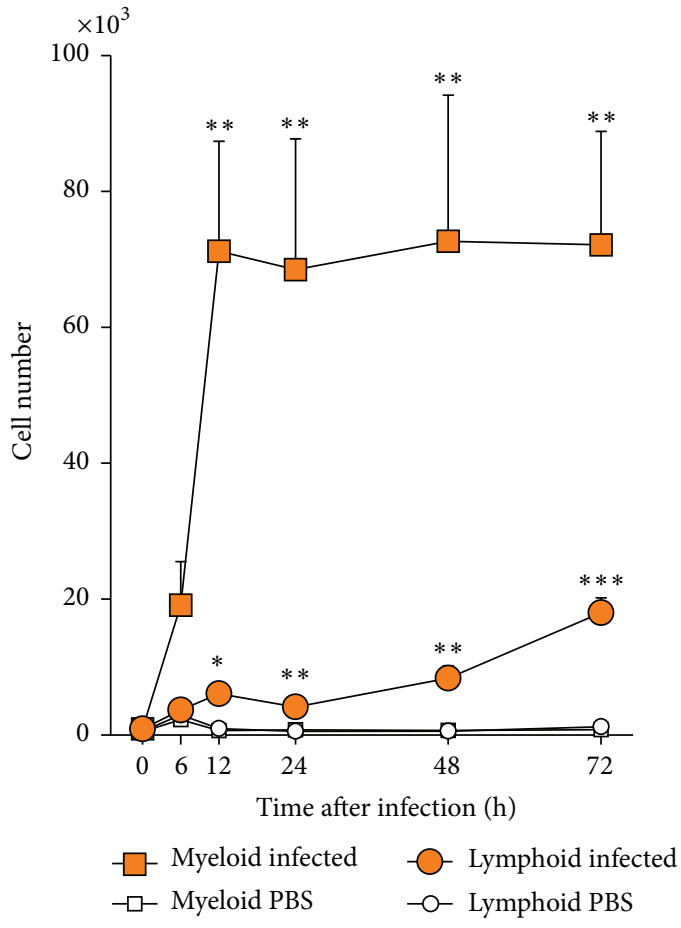

(b)

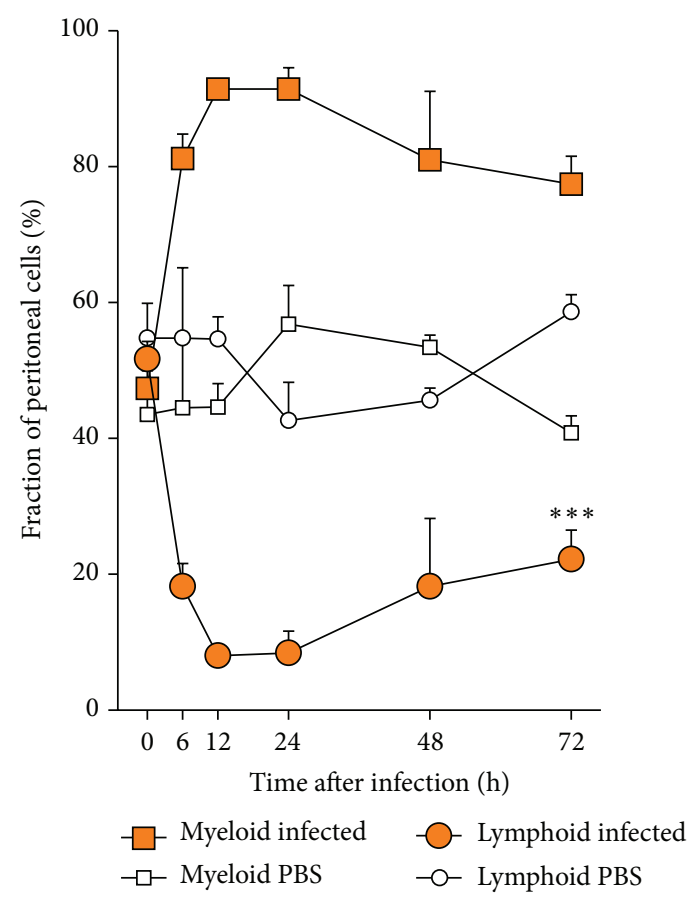

(c)

FIgURE 5: Kinetics of leukocyte recruitment into the peritoneum after infection with A. salmonicida. (a) The total number of leukocytes in the peritoneal fluid in infected trout (filled bars) and PBS-injected controls (open bars) was determined with flow cytometry and is given as mean \pm SEM from five fish per time point (ordinate). (b) Differentiation of the number of recruited cells into myeloid cells (square symbols) and lymphocytes (circles). (c) Alteration of the percentage of myeloid cells (square symbols) and lymphocytes (circles) after PBS injection (open symbols) or infection with $A$. salmonicida (filled symbols) as calculated from the data given in (b). Asterisks denote statistical significance with $p<0.001(* * *), p<0.01(* *)$, and $p<0.05(*)$, compared to controls ( 0 hpi), assessed with one-way ANOVA, followed by Tukey's post hoc test.

modulated by a variety of apparently unrelated signals. It was significantly upregulated in several tissues and immune cells after infection and/or stimulation (i) with Gram-negative bacteria, that is, Aeromonas sp. in trout [47], in goldfish Carassius auratus [48], and in rohu Labeo rohita [49], as well as with Vibrio anguillarum in sea bream Sparus aurata [50]; (ii) with Gram-positive Mycobacterium chelonae in C. auratus
[48]; (iii) with reovirus in grass carp Ctenopharyngodon idella [51, 52]; and (vi) with the ectoparasite Argulus siamensis in common carp Cyprinus carpio [53]. The broad spectrum of apparent "ligands" for this factor suggests that its interaction with MAMPs can structurally not be similar to the sophisticated key-lock principal as known from mammalian TLRs interacting with their specific ligands $[54,55]$. Perhaps 
TABLE 4: Expression profiles of $\mathrm{T}$ and $\mathrm{B}$ cell marker genes in selected tissues of rainbow trout at different time points after infection.

\begin{tabular}{|c|c|c|c|c|c|c|}
\hline \multirow{2}{*}{ Gene symbol } & \multirow{2}{*}{ Tissues } & \multicolumn{5}{|c|}{ Fold change values at time points after infection relative to control } \\
\hline & & $6 \mathrm{~h}$ & $12 \mathrm{~h}$ & $24 \mathrm{~h}$ & $48 \mathrm{~h}$ & $72 \mathrm{~h}$ \\
\hline \multirow{4}{*}{$\operatorname{trb}$} & Spleen & $-1.55 \pm 0.27$ & $-2.00 \pm 0.34^{*}$ & $-1.95 \pm 0.64^{*}$ & $-1.66 \pm 0.27$ & $-2.76 \pm 0.45^{*}$ \\
\hline & Head kidney & $1.53 \pm 0.26$ & $-1.35 \pm 0.31$ & $4.01 \pm 1.25$ & $8.94 \pm 2.59$ & $11.78 \pm 2.60$ \\
\hline & Liver & $-1.10 \pm 0.40$ & $-1.01 \pm 0.35$ & $2.80 \pm 1.82$ & $-1.50 \pm 0.57$ & $-1.47 \pm 0.57$ \\
\hline & Thymus & $-1.05 \pm 0.26$ & $-1.48 \pm 0.39$ & $-2.78 \pm 0.87$ & $-1.42 \pm 0.37$ & $-1.23 \pm 0.28$ \\
\hline \multirow{4}{*}{ igm } & Spleen & $-1.26 \pm 0.31$ & $-1.51 \pm 0.33$ & $-1.37 \pm 0.34$ & $1.09 \pm 0.33$ & $-1.67 \pm 0.45$ \\
\hline & Head kidney & $1.11 \pm 0.26$ & $-1.30 \pm 0.29$ & $-\mathbf{1 0 . 2 6} \pm 4.95^{*}$ & $-\mathbf{9 . 6 4} \pm 1.96^{*}$ & $-11.19 \pm 2.19^{*}$ \\
\hline & Liver & $1.01 \pm 0.35$ & $-1.24 \pm 0.42$ & $2.26 \pm 0.81$ & $1.43 \pm 0.52$ & $1.43 \pm 0.48$ \\
\hline & Thymus & $1.23 \pm 0.28$ & $1.06 \pm 0.36$ & $2.92 \pm 1.08^{*}$ & $2.42 \pm 0.54$ & $2.42 \pm 0.45$ \\
\hline
\end{tabular}

* Significant expression difference $(p<0.05)$ between the infected and the control groups is indicated in bold.

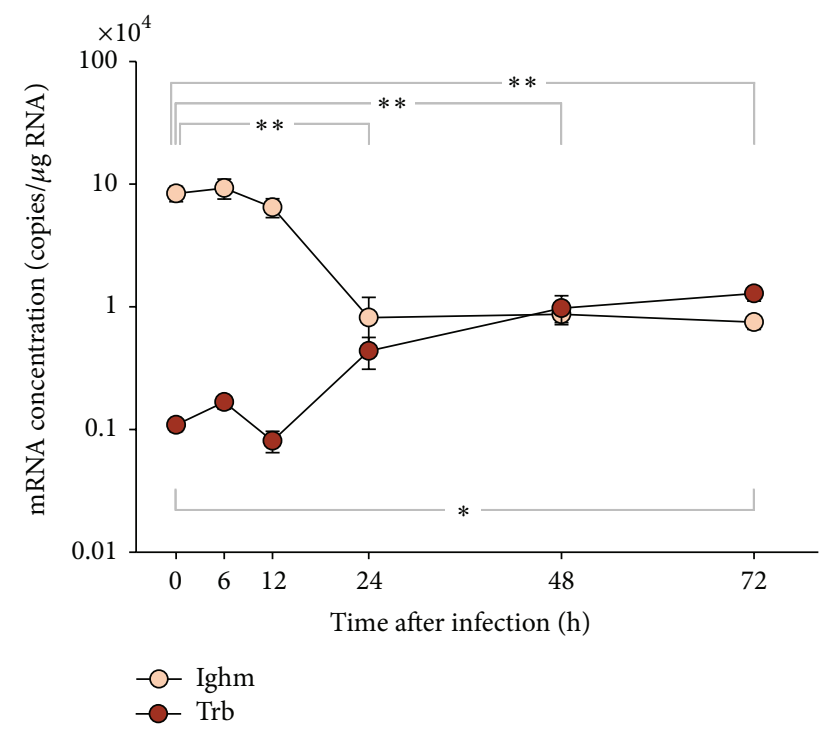

Figure 6: Dynamics of $\mathrm{T}$ and $\mathrm{B}$ cell migration in head kidney after infection. Ordinate shows the relative number of mRNA copies (per $\mu$ g total RNA) encoding the T cell receptor beta (TRB) and immunoglobulin $\mathrm{M}$ (Ighm) inhead kidney of five individuals/time point at various times after infection (abscissa). Values are given as mean \pm SEM. Note that the relative quantity is presented on a log10 scale. Asterisks denote statistical significance with $p<0.01(* *)$ and $p<0.05(*)$ compared to controls above $(\mathrm{ighm})$ and below $(\mathrm{trb})$ the graph. Statistical significance was assessed with a double sided $t$-test.

trout Tlr22a2 senses some endogenous DAMPs resulting from Aeromonas-induced traumata rather than exogenous MAMPs as previously discussed by Ingerslev et al. [14]. However, assuming ligand-independent activation of Tlr22a2 expression is even more puzzling since we noted in our original description of the twin receptors Tlr22al and Tlr22a2 [47] that both factors share a high degree of identical amino acid residues (94\%), with most of the few exchanged residues being located in the $\mathrm{N}$-terminal, distal leucine-rich repeat region (LRR). LRRs are known as ligand-binding areas of TLRs. We also note that the expression of both Tlr22a twin factors is not coregulated since only one of them was upregulated.
4.2. Irak1 May Have a Peculiar Role for Constraining tlr Signaling in Trout. Our candidate factors contributing downstream to $t$ tr signaling were eventually upregulated in the livers of infected fish and none of them was significantly downregulated at any time after infection. Upregulated mRNA concentrations of such factors in liver were reported from a variety of challenge studies and infection experiments in different fish species [56-59]. Irak1 was distinct from all those other factors in so far as its mRNA abundance was increased already at $6 \mathrm{hpi}$, not only in liver, but also in spleen and head kidney. Early stimulation of the expression of this factor in several immune organs connects its activation to the very early events of mounting an immune defense. A prominent function of IRAK1 in mammals is its integration into the Myddosome, which is built up around the activated TIR domain of TLRs [8]. Viral infection of the grass carp was demonstrated to recruit Irak1 to the cell membrane possibly indicating that it is recruited to transmembrane TLRs [58]. Relating this information with our data could suggest that rate-limiting low levels of irakl factors might constrain TLR signaling in healthy trout and its organs. Given the absence of strong transcriptional tlr regulation in trout, this would conceptually allow shifting the regulatory level of the TLR signaling cascade away from the transcriptional regulation of some key receptors (such as TLR2 and TLR4 in mammals) towards the expression level of rate-limiting downstream factors.

Moreover, IRAK1 is also the factor being functionally inactivated by TOLLIP $[58,60]$. Intriguingly enough, we found a consistent and significant upregulation of tollip expression in liver from $24 \mathrm{hpi}$ onwards. This conceivably reflects the dampening of the synthesis of acute-phase factors. Hence, the data altogether allow the conclusion that Irak1 plays a prominent role in controlling the activity of TLR signaling in trout. Clearly, validation of this hypothesis would require a different experimental approach.

4.3. Trout Combats A. salmonicida Infection through Fast Recruitment of Myeloid Cells. Fast and strong recruitment of myeloid cells into the peritoneum indicates that the infected fish were prepared to combat the infectious pathogens. This almost instantaneous reaction against the invaders was in stark contrast to the sluggish modulation of the expression of 
factors contributing to the TLR signaling cascade. Recognizing the presence of pathogens by the host activated vibrantly the immune defense. The first step consisted of mounting a massive cellular defense to fight off the bacteria rather than inducing resilience or tolerance. Those myeloid cells (conceivably monocytes/macrophages and granulocytes), having been recruited into the peritoneum, belong to the cellular arm of innate immune defense. The second step of harnessing cellular immune mechanisms consisted of activating lymphoid cells, which belong to the adaptive branch of immune defense. The activation of adaptive immunity involves timeconsuming processes such as induction of cell proliferation and cellular redifferentiation. Only then, significant amounts of cells might start migrating out from their site of proliferation and maturation to the site of infection. Our RT-qPCR data suggest belated onset of adaptive immunity, which was not surprising. It took more than $12 \mathrm{hpi}$ for a considerable amount of the cells of the B-type lineage to probably move out from their reservoir in the head kidney [61] into the peritoneum. At the same time, the Tlymphocytes presumably started moving into this organ, conceivably to be functionally primed by relevant antigen-presenting cells.

\section{Conclusions}

The presence of infectious $A$. salmonicida is quickly recognized by trout since the expression of key cytokine-encoding genes is instantaneously induced. However, even the severe infection with high doses of this Gram-negative pathogen only modestly regulated the expression of most $t l r$ genes in immune organs indicating a mainly constitutive expression of these factors. We suggest that the limited abundance of Irak1 constrains their activity. No specific TLR could be singled out as a dominant receptor for perceiving the presence of $A$. salmonicida, albeit that Tlr22a2 was quickly and strongly induced after infection. Rather, this factor is known to be regulated by several nonrelated stimuli and might serve as unspecific alarm switch. The massive recruitment of granulocytes and monocytes/macrophages into the peritoneum highlights their pivotal importance. Hence, recruitment of cellular factors of innate immunity rather than induced expression of pathogen receptors is of key importance for mounting a first immune defense against invading $A$. salmonicida.

\section{Abbreviations}

$\begin{array}{ll}\text { hpi: } & \text { Hours postinfection } \\ \text { Ig: } & \text { Immunoglobulin } \\ \text { IL: } & \text { Interleukin } \\ \text { IRAK: } & \text { Interleukin-1 receptor-associated kinase } \\ \text { LRR: } & \text { Leucine-rich repeat region } \\ \text { MYD88: } & \begin{array}{l}\text { Myeloid differentiation primary response } \\ \text { protein } 88\end{array} \\ \text { NOD1: } & \begin{array}{l}\text { Nucleotide-binding oligomerization } \\ \text { domain-containing protein } 1\end{array} \\ \text { PBS: } & \begin{array}{l}\text { Phosphate-buffered saline } \\ \text { RT-qPCR: }\end{array} \\ & \text { Quantitative real-time reverse transcription } \\ & \text { polymerase chain reaction }\end{array}$

TGFB: Transforming growth factor beta

TIR: Toll/interleukin-1 receptor domain

TLR: Toll-like receptor

TNF: Tumor necrosis factor (alpha)

TOLLIP: Toll-interacting protein

TRAF6: TNF receptor-associated factor 6

TRB: $\quad$ T cell receptor beta locus.

\section{Conflict of Interests}

The authors declare that they have no conflict of interests.

\section{Authors' Contribution}

Andreas Brietzke and Tomáš Korytář contributed equally to this work.

\section{Acknowledgments}

The authors are grateful to A. Deike, B. Pletz, I. Hennings, B. Schöpel, and S. Weber for excellent technical assistance. This work was funded by the DFG-Grant SE 326/16-1 from the German Research Foundation.

\section{References}

[1] P. R. Rauta, B. Nayak, and S. Das, "Immune system and immune responses in fish and their role in comparative immunity study: a model for higher organisms," Immunology Letters, vol. 148, no. 1, pp. 23-33, 2012.

[2] M. E. Bianchi, "DAMPs, PAMPs and alarmins: all we need to know about danger," Journal of Leukocyte Biology, vol. 81, no. 1, pp. 1-5, 2007.

[3] A. Kaczmarek, P. Vandenabeele, and D. V. Krysko, "Necroptosis: the release of damage-associated molecular patterns and its physiological relevance," Immunity, vol. 38, no. 2, pp. 209-223, 2013.

[4] R. Gill, A. Tsung, and T. Billiar, "Linking oxidative stress to inflammation: toll-like receptors," Free Radical Biology \& Medicine, vol. 48, no. 9, pp. 1121-1132, 2010.

[5] J. Zhang, X. Kong, C. Zhou, L. Li, G. Nie, and X. Li, “Toll-like receptor recognition of bacteria in fish: ligand specificity and signal pathways," Fish and Shellfish Immunology, vol. 41, no. 2, pp. 380-388, 2014.

[6] A. Rebl, T. Goldammer, and H.-M. Seyfert, "Toll-like receptor signaling in bony fish," Veterinary Immunology and Immunopathology, vol. 134, no. 3-4, pp. 139-150, 2010.

[7] J. C. Roach, G. Glusman, L. Rowen et al., "The evolution of vertebrate Toll-like receptors," Proceedings of the National Academy of Sciences of the United States of America, vol. 102, no. 27, pp. 9577-9582, 2005.

[8] S.-C. Lin, Y.-C. Lo, and H. Wu, "Helical assembly in the MyD88IRAK4-IRAK2 complex in TLR/IL-1R signalling," Nature, vol. 465, no. 7300, pp. 885-890, 2010.

[9] A. Brietzke, T. Goldammer, H. Rebl et al., "Characterization of the interleukin 1 receptor-associated kinase 4 (IRAK4)encoding gene in salmonid fish: the functional copy is rearranged in Oncorhynchus mykiss and that factor can impair TLR signaling in mammalian cells," Fish and Shellfish Immunology, vol. 36, no. 1, pp. 206-214, 2014. 
[10] T. Kawai and S. Akira, "Toll-like receptor and RIG-1-like receptor signaling," Annals of the New York Academy of Sciences, vol. 1143, pp. 1-20, 2008.

[11] M. P. Belvin and K. V. Anderson, "A conserved signaling pathway: the Drosophila toll-dorsal pathway," Annual Review of Cell and Developmental Biology, vol. 12, pp. 393-416, 1996.

[12] N. J. Patterson and D. Werling, "To con protection: TIRdomain containing proteins (Tcp) and innate immune evasion," Veterinary Immunology and Immunopathology, vol. 155, no. 3, pp. 147-154, 2013.

[13] J. G. Daly, A. K. Kew, A. R. Moore, and G. Olivier, "The cell surface of Aeromonas salmonicida determines in vitro survival in cultured brook trout (Salvelinus fontinalis) peritoneal macrophages," Microbial Pathogenesis, vol. 21, no. 6, pp. 447461, 1996.

[14] H. C. Ingerslev, T. Lunder, and M. E. Nielsen, "Inflammatory and regenerative responses in salmonids following mechanical tissue damage and natural infection," Fish \& Shellfish Immunology, vol. 29, no. 3, pp. 440-450, 2010.

[15] B. Robertsen, "The interferon system of teleost fish," Fish \& Shellfish Immunology, vol. 20, no. 2, pp. 172-191, 2006.

[16] J. D. Hansen, L. N. Vojtech, and K. J. Laing, "Sensing disease and danger: a survey of vertebrate PRRs and their origins," Developmental and Comparative Immunology, vol. 35, no. 9, pp. 886-897, 2011.

[17] A. Matsuo, H. Oshiumi, T. Tsujita et al., "Teleost TLR22 recognizes RNA duplex to induce IFN and protect cells from birnaviruses," Journal of Immunology, vol. 181, no. 5, pp. 34743485, 2008.

[18] M. Arnemo, A. Kavaliauskis, and T. Gjøen, "Effects of TLR agonists and viral infection on cytokine and TLR expression in Atlantic salmon (Salmo salar)," Developmental and Comparative Immunology, vol. 46, no. 2, pp. 139-145, 2014.

[19] F. Zhao, Y.-W. Li, H.-J. Pan et al., "Expression profiles of toll-like receptors in channel catfish (Ictalurus punctatus) after infection with Ichthyophthirius multifiliis," Fish \& Shellfish Immunology, vol. 35, no. 3, pp. 993-997, 2013.

[20] D. H. Ahn, S. C. Shin, and H. Park, "Characterization of Toll-like receptor gene expression and the pathogen agonist response in the antarctic bullhead notothen Notothenia coriiceps," Immunogenetics, vol. 66, no. 9-10, pp. 563-573, 2014.

[21] C. L. Fuller, K. C. Brittingham, M. W. Porter et al., "Transcriptome analysis of human immune responses following live vaccine strain (LVS) Francisella tularensis vaccination," Molecular Immunology, vol. 44, no. 12, pp. 3173-3184, 2007.

[22] H. Tsujimoto, S. Ono, T. Majima et al., "Neutrophil elastase, MIP-2, and TLR-4 expression during human and experimental sepsis," Shock, vol. 23, no. 1, pp. 39-44, 2005.

[23] T. Okabayashi, H. Kariwa, S.-I. Yokota et al., "Cytokine regulation in SARS coronavirus infection compared to other respiratory virus infections," Journal of Medical Virology, vol. 78, no. 4, pp. 417-424, 2006.

[24] B. Beutler and E. T. Rietschel, "Innate immune sensing and its roots: the story of endotoxin," Nature Reviews Immunology, vol. 3, no. 2, pp. 169-176, 2003.

[25] D. B. Iliev, J. C. Roach, S. Mackenzie, J. V. Planas, and F. W. Goetz, "Endotoxin recognition: in fish or not in fish?" FEBS Letters, vol. 579, no. 29, pp. 6519-6528, 2005.

[26] D. Pietretti and G. F. Wiegertjes, "Ligand specificities of Tolllike receptors in fish: indications from infection studies," Developmental and Comparative Immunology, vol. 43, no. 2, pp. 205222, 2014.
[27] A. Rebl, T. Goldammer, U. Fischer, B. Köllner, and H.-M. Seyfert, "Characterization of two key molecules of teleost innate immunity from rainbow trout (Oncorhynchus mykiss): MyD88 and SAA," Veterinary Immunology and Immunopathology, vol. 131, no. 1-2, pp. 122-126, 2009.

[28] A. Rebl, B. Høyheim, U. Fischer, B. Köllner, E. Siegl, and H.M. Seyfert, "Tollip, a negative regulator of TLR-signalling, is encoded by twin genes in salmonid fish," Fish and Shellfish Immunology, vol. 25, no. 1-2, pp. 153-162, 2008.

[29] T. Korytáŕ, J. Jaros, M. Verleih et al., "Novel insights into the peritoneal inflammation of rainbow trout (Oncorhynchus mykiss)," Fish and Shellfish Immunology, vol. 35, no. 4, pp. 11921199, 2013.

[30] S. B. Park, J.-I. Hikima, Y. Suzuki et al., "Molecular cloning and functional analysis of nucleotide-binding oligomerization domain 1 (NOD1) in olive flounder, Paralichthys olivaceus," Developmental and Comparative Immunology, vol. 36, no. 4, pp. 680-687, 2012.

[31] J. Zou, P. S. Grabowski, C. Cunningham, and C. J. Secombes, "Molecular cloning of interleukin $1 \beta$ from rainbow trout Oncorhynchus mykiss reveals no evidence of an ice cut site," Cytokine, vol. 11, no. 8, pp. 552-560, 1999.

[32] O. Pleguezuelos, J. Zou, C. Cunningham, and C. J. Secombes, "Cloning, sequencing, and analysis of expression of a second ILlbeta gene in rainbow trout (Oncorhynchus mykiss)," Immunogenetics, vol. 51, no. 12, pp. 1002-1011, 2000.

[33] K. J. Laing, T. Wang, J. Zou et al., "Cloning and expression analysis of rainbow trout Oncorhynchus mykiss tumour necrosis factor- $\alpha$," European Journal of Biochemistry, vol. 268, no. 5, pp. 1315-1322, 2001.

[34] K. J. Laing, J. J. Zou, T. H. Wang et al., "Identification and analysis of an interleukin 8-like molecule in rainbow trout Oncorhynchus mykiss," Developmental and Comparative Immunology, vol. 26, no. 5, pp. 433-444, 2002.

[35] A. Rebl, H. Rebl, T. Korytáŕ, T. Goldammer, and H.-M. Seyfert, "The proximal promoter of a novel interleukin-8-encoding gene in rainbow trout (Oncorhynchus mykiss) is strongly induced by CEBPA, but not NF- $\kappa$ B p65," Developmental and Comparative Immunology, vol. 46, no. 2, pp. 155-164, 2014.

[36] Y. Inoue, S. Kamota, K. Ito et al., "Molecular cloning and expression analysis of rainbow trout (Oncorhynchus mykiss) interleukin-10 cDNAs," Fish and Shellfish Immunology, vol. 18, no. 4, pp. 335-344, 2005.

[37] L. J. Hardie, K. J. Laing, G. D. Daniels, P. S. Grabowski, C. Cunningham, and C. J. Secombes, "Isolation of the first piscine transforming growth factor $\beta$ gene: analysis reveals tissue specific expression and a potential regulatory sequence in rainbow trout (Oncorhynchus mykiss)," Cytokine, vol. 10, no. 8, pp. 555-563, 1998.

[38] R. Sabat, G. Grütz, K. Warszawska et al., "Biology of interleukin10," Cytokine \& Growth Factor Reviews, vol. 21, no. 5, pp. 331344, 2010.

[39] D. Bernard, A. Six, L. Rigottier-Gois et al., "Phenotypic and functional similarity of gut intraepithelial and systemic T cells in a teleost fish," Journal of Immunology, vol. 176, no. 7, pp. 39423949, 2006.

[40] A. Visintin, A. Mazzoni, J. H. Spitzer, D. H. Wyllie, S. K. Dower, and D. M. Segal, "Regulation of Toll-like receptors in human monocytes and dendritic cells," Journal of Immunology, vol. 166, no. 1, pp. 249-255, 2001. 
[41] B. Schwanhäusser, D. Busse, N. Li et al., "Global quantification of mammalian gene expression control," Nature, vol. 473, no. 7347, pp. 337-342, 2011.

[42] I. Skjæveland, D. B. Iliev, J. Zou, T. Jørgensen, and J. B. Jørgensen, "A TLR9 homolog that is up-regulated by IFN- $\gamma$ in Atlantic salmon (Salmo salar)," Developmental and Comparative Immunology, vol. 32, no. 6, pp. 603-607, 2008.

[43] X. Hu, J. Chen, L. Wang, and L. B. Ivashkiv, "Crosstalk among Jak-STAT, Toll-like receptor, and ITAM-dependent pathways in macrophage activation," Journal of Leukocyte Biology, vol. 82, no. 2, pp. 237-243, 2007.

[44] B. Abós, R. Castro, J. Pignatelli, A. Luque, L. González, and C. Tafalla, "Transcriptional heterogeneity of $\operatorname{IgM}^{+}$cells in rainbow trout (Oncorhynchus mykiss) tissues," PLoS ONE, vol. 8, no. 12, Article ID e82737, 2013.

[45] A. Deepika, K. Sreedharan, A. Paria, M. Makesh, and K. V. Rajendran, "Toll-pathway in tiger shrimp (Penaeus monodon) responds to white spot syndrome virus infection: evidence through molecular characterisation and expression profiles of MyD88, TRAF6 and TLR genes," Fish and Shellfish Immunology, vol. 41, no. 2, pp. 441-454, 2014.

[46] P.-H. Wang, J.-P. Liang, Z.-H. Gu et al., "Molecular cloning, characterization and expression analysis of two novel Tolls (LvToll2 and LvToll3) and three putative Spätzle-like Toll ligands (LvSpzl-3) from Litopenaeus vannamei," Developmental and Comparative Immunology, vol. 36, no. 2, pp. 359-371, 2012.

[47] A. Rebl, E. Siegl, B. Köllner, U. Fischer, and H.-M. Seyfert, "Characterization of twin toll-like receptors from rainbow trout (Oncorhynchus mykiss): evolutionary relationship and induced expression by Aeromonas salmonicida salmonicida," Developmental and Comparative Immunology, vol. 31, no. 5, pp. 499-510, 2007.

[48] J. L. Stafford, K. K. Ellestad, K. E. Magor, M. Belosevic, and B. G. Magor, "A toll-like receptor (TLR) gene that is upregulated in activated goldfish macrophages," Developmental and Comparative Immunology, vol. 27, no. 8, pp. 685-698, 2003.

[49] M. Samanta, B. Swain, M. Basu et al., “Toll-like receptor 22 in Labeo rohita: molecular cloning, characterization, 3D modeling, and expression analysis following ligands stimulation and bacterial infection," Applied Biochemistry and Biotechnology, vol. 174, no. 1, pp. 309-327, 2014.

[50] I. Muñoz, M. P. Sepulcre, J. Meseguer, and V. Mulero, “Tolllike receptor 22 of gilthead seabream, Sparus aurata: molecular cloning, expression profiles and post-transcriptional regulation," Developmental and Comparative Immunology, vol. 44, no. 1, pp. 173-179, 2014.

[51] J. Lv, R. Huang, H. Li et al., "Cloning and characterization of the grass carp (Ctenopharyngodon idella) Toll-like receptor 22 gene, a fish-specific gene," Fish \& Shellfish Immunology, vol. 32, no. 6, pp. 1022-1031, 2012.

[52] Y. Rao and J. Su, "Insights into the antiviral immunity against grass carp (Ctenopharyngodon idella) reovirus (GCRV) in grass carp," Journal of Immunology Research, vol. 2015, Article ID 670437, 18 pages, 2015.

[53] R. P. Panda, V. Chakrapani, S. K. Patra et al., "First evidence of comparative responses of Toll-like receptor 22 (TLR22) to relatively resistant and susceptible Indian farmed carps to Argulus siamensis infection," Developmental and Comparative Immunology, vol. 47, no. 1, pp. 25-35, 2014.

[54] B. S. Park, D. H. Song, H. M. Kim, B.-S. Choi, H. Lee, and J.-O. Lee, "The structural basis of lipopolysaccharide recognition by the TLR4-MD-2 complex," Nature, vol. 458, no. 7242, pp. 1191$1195,2009$.

[55] B. Manavalan, S. Basith, and S. Choi, "Similar structures but different roles-an updated perspective on TLR structures," Frontiers in Physiology, vol. 2, article 41, 2011.

[56] J. Wei, M. Guo, P. Gao et al., "Isolation and characterization of tumor necrosis factor receptor-associated factor 6 (TRAF6) from grouper, Epinephelus tauvina," Fish \& Shellfish Immunology, vol. 39, no. 1, pp. 61-68, 2014.

[57] Y. Yu, Q. Zhong, C. Li et al., "Identification and characterization of IL-1 receptor-associated kinase-4 (IRAK-4) in half-smooth tongue sole Cynoglossus semilaevis," Fish \& Shellfish Immunology, vol. 32, no. 4, pp. 609-615, 2012.

[58] R. Huang, J. Lv, D. Luo, L. Liao, Z. Zhu, and Y. Wang, "Identification, characterization and the interaction of Tollip and IRAK-1 in grass carp (Ctenopharyngodon idellus)," Fish and Shellfish Immunology, vol. 33, no. 3, pp. 459-467, 2012.

[59] C.-Z. Zhang, Z.-X. Yin, W. He et al., "Cloning of IRAK1 and its upregulation in symptomatic mandarin fish infected with ISKNV,' Biochemical and Biophysical Research Communications, vol. 383, no. 3, pp. 298-302, 2009.

[60] Y. Bulut, E. Faure, L. Thomas, O. Equils, and M. Arditi, "Cooperation of Toll-like receptor 2 and 6 for cellular activation by soluble tuberculosis factor and Borrelia burgdorferi outer surface protein a lipoprotein: role of Toll-interacting protein and IL-1 receptor signaling molecules in Toll-like receptor 2 signaling," The Journal of Immunology, vol. 167, no. 2, pp. 987994, 2001.

[61] J. D. Hansen and A. G. Zapata, "Lymphocyte development in fish and amphibians," Immunological Reviews, vol. 166, pp. 199220, 1998. 


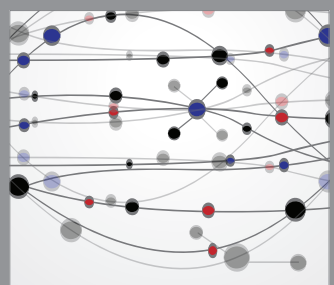

The Scientific World Journal
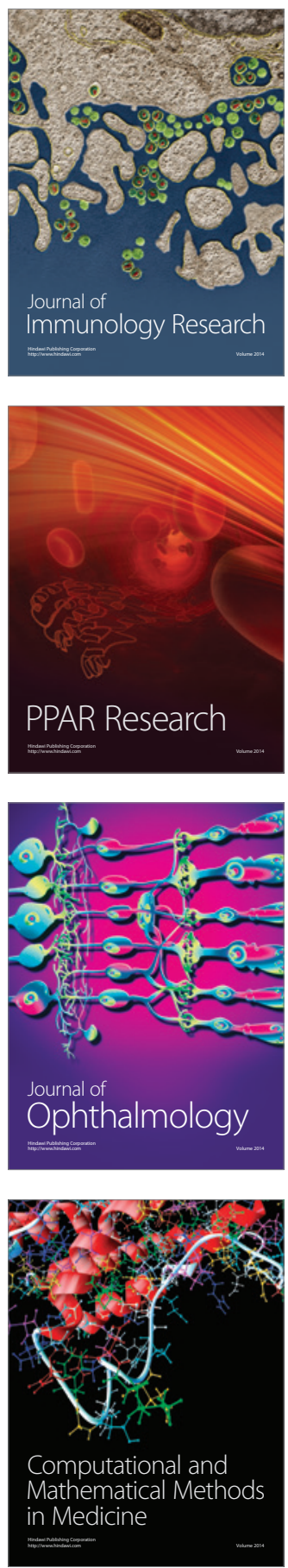

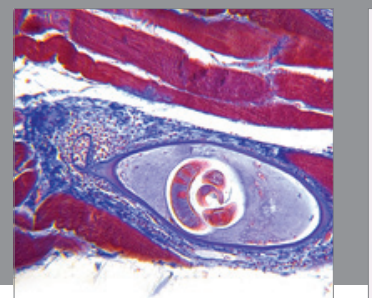

Gastroenterology

Research and Practice
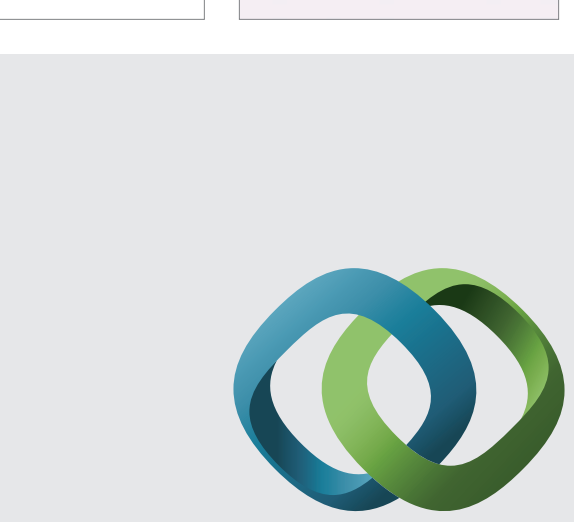

\section{Hindawi}

Submit your manuscripts at

http://www.hindawi.com
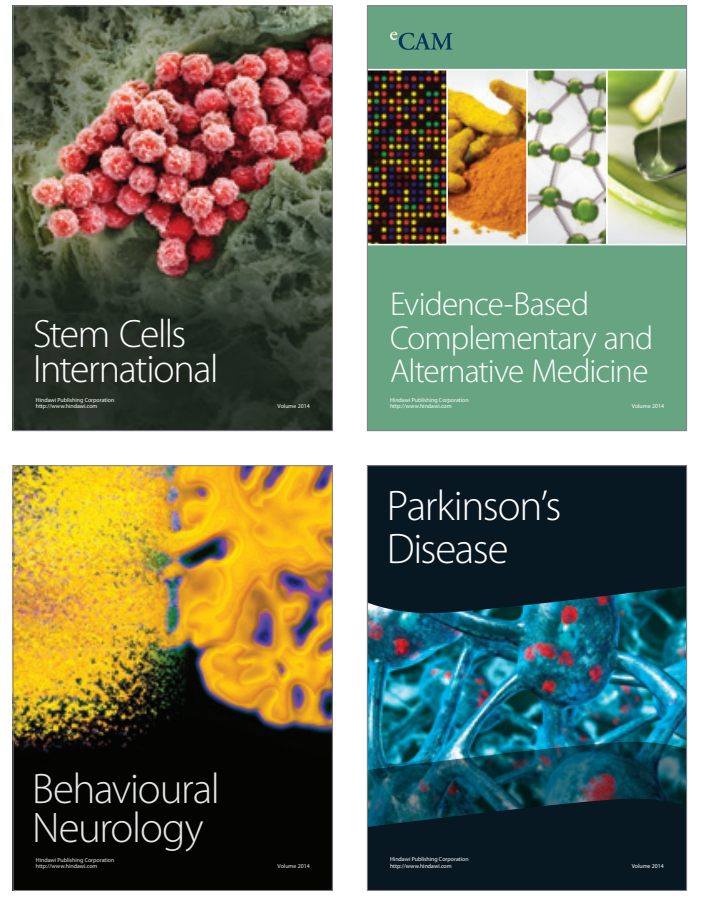
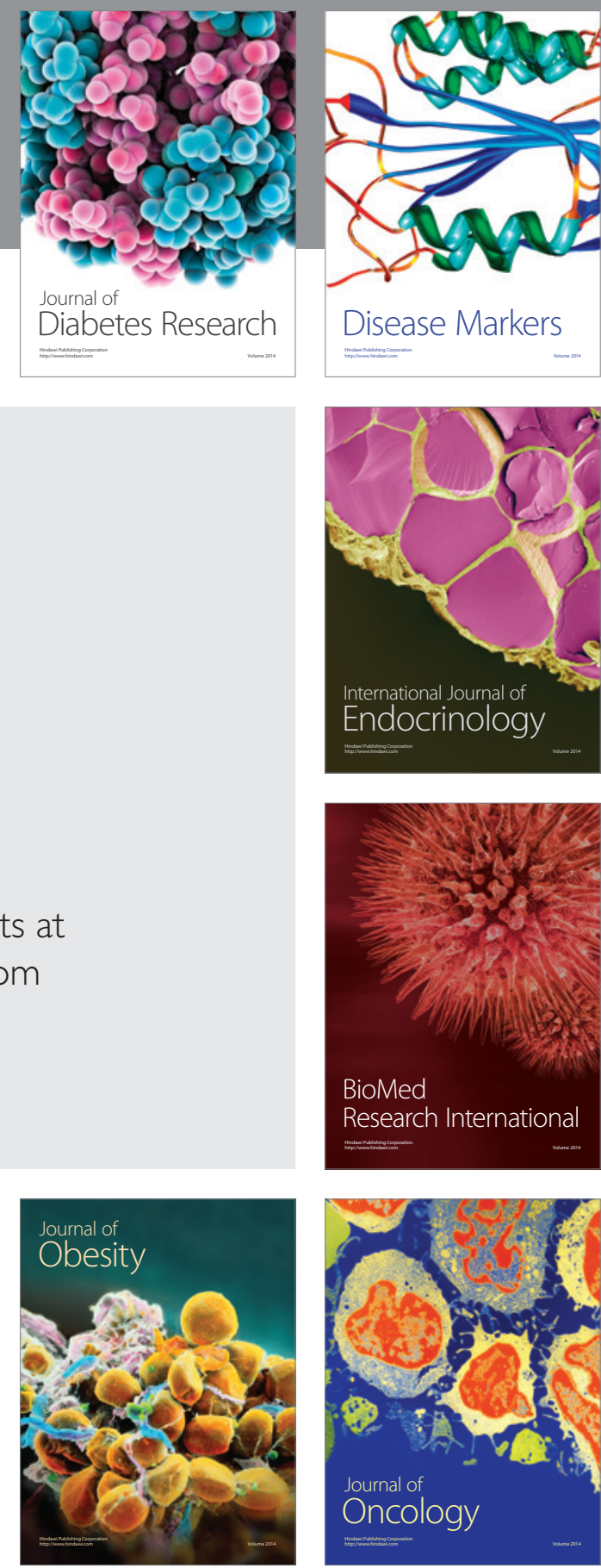

Disease Markers
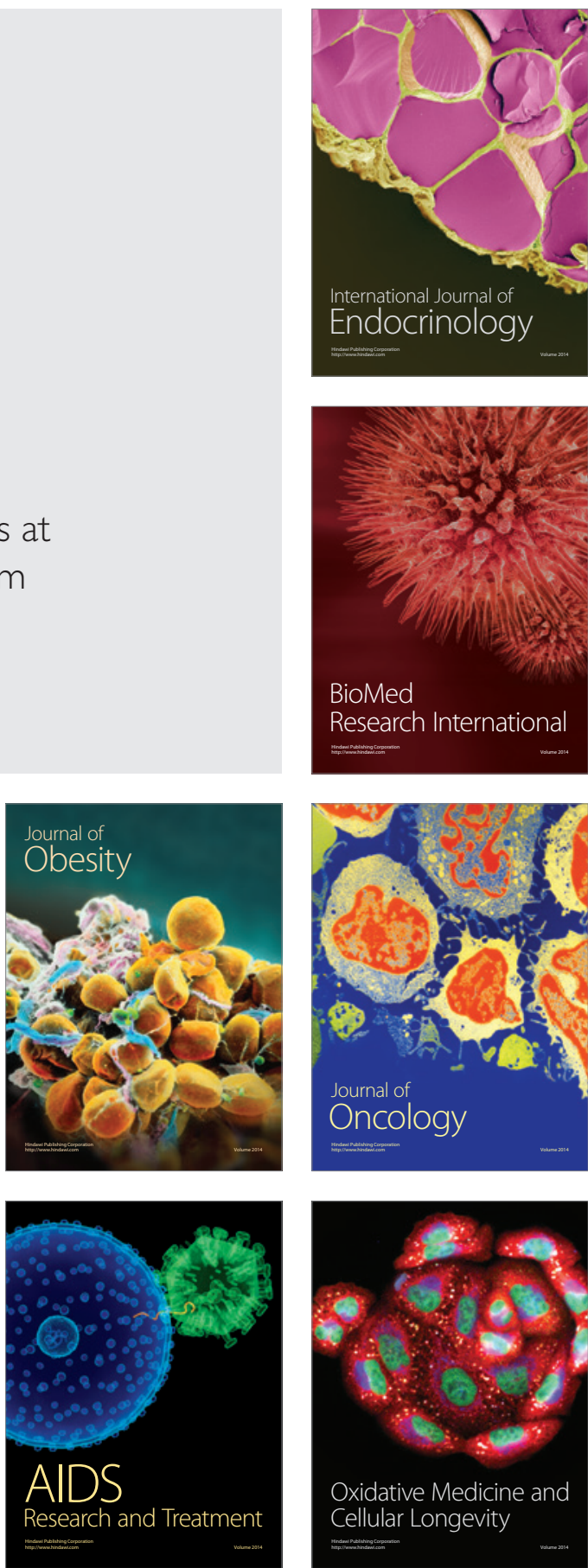